\title{
Snail-induced epithelial-to-mesenchymal transition of MCF-7 breast cancer cells: systems analysis of molecular changes and their effect on radiation and drug sensitivity
}

\author{
Roman Mezencev, Lilya V. Matyunina, Neda Jabbari and John F. McDonald*
}

\begin{abstract}
Background: Epithelial-to-mesenchymal transition (EMT) has been associated with the acquisition of metastatic potential and the resistance of cancer cells to therapeutic treatments. MCF-7 breast cancer cells engineered to constitutively express the zinc-finger transcriptional repressor gene Snail (MCF-7-Snail cells) have been previously shown to display morphological and molecular changes characteristic of EMT. We report here the results of a comprehensive systems level molecular analysis of changes in global patterns of gene expression and levels of glutathione and reactive oxygen species (ROS) in MCF-7-Snail cells and the consequence of these changes on the sensitivity of cells to radiation treatment and therapeutic drugs.

Methods: Snail-induced changes in global patterns of gene expression were identified by microarray profiling using the Affymetrix platform (U133 Plus 2.0). The resulting data were processed and analyzed by a variety of system level analytical methods. Levels of ROS and glutathione (GSH) were determined by fluorescent and luminescence assays, and nuclear levels of NF-KB protein were determined by an ELISA based method. The sensitivity of cells to ionizing radiation and anticancer drugs was determined using a resazurin-based cell cytotoxicity assay.
\end{abstract}

Results: Constitutive ectopic expression of Snail in epithelial-like, luminal A-type MCF-7 cells induced significant changes in the expression of $>7600$ genes including gene and miRNA regulators of EMT. Mesenchymal-like MCF-7-Snail cells acquired molecular profiles characteristic of triple-negative, claudin-low breast cancer cells, and displayed increased sensitivity to radiation treatment, and increased, decreased or no change in sensitivity to a variety of anticancer drugs. Elevated ROS levels in MCF-7-Snail cells were unexpectedly not positively correlated with NF-KB activity.

Conclusions: Ectopic expression of Snail in MCF-7 cells resulted in morphological and molecular changes previously associated with EMT. The results underscore the complexity and cell-type dependent nature of the EMT process and indicate that EMT is not necessarily predictive of decreased resistance to radiation and drug-based therapies.

Keywords: Epithelial-to-mesenchymal transition, Snail, Slug, NF-kB, Drug resistance, Radiation sensitivity, MCF-7, Triple-negative breast-cancer, Reactive oxygen species, Glutathione

\footnotetext{
* Correspondence: john.mcdonald@biology.gatech.edu

Integrated Cancer Research Center, School of Biology, and Parker H. Petit

Institute of Bioengineering and Biosciences, Georgia Institute of Technology,

315 Ferst Dr., Atlanta, GA 30332, USA
}

\section{$\int$ Biomed Central}

(c) 2016 Mezencev et al. Open Access This article is distributed under the terms of the Creative Commons Attribution 4.0 International License (http://creativecommons.org/licenses/by/4.0/), which permits unrestricted use, distribution, and reproduction in any medium, provided you give appropriate credit to the original author(s) and the source, provide a link to the Creative Commons license, and indicate if changes were made. The Creative Commons Public Domain Dedication waiver (http://creativecommons.org/publicdomain/zero/1.0/) applies to the data made available in this article, unless otherwise stated. 


\section{Background}

Breast cancer is the most common female malignancy worldwide with an estimated 1.67 million new cases in 2012 [1]. Despite significant recent progress in the diagnosis and treatment of this biologically and clinically heterogeneous disease, breast cancer remains the most frequent cause of cancer death among women in less developed regions of the world and the second-leading cause of cancer death among women in developed nations $[1,2]$. As is the case with most cancers, breast cancer-related deaths are primarily due to metastasis. Metastatic breast cancer $(\mathrm{MBC})$ is present in $\sim 6 \%$ of patients at the time of initial diagnosis and eventually develops in $20-50 \%$ of all breast cancer patients [2]. Since $\mathrm{MBC}$ is currently an incurable condition with median survival time of only $0.5-2.2$ years, depending on subtype [3], it continues to be a challenging problem in both basic and clinical cancer research.

Epithelial-to-mesenchymal transition (EMT) is an essential process in normal embryonic development $[4,5]$ and has been associated with the acquisition of metastatic potential $[6,7]$ and the resistance of breast and other types of cancers to ionizing radiation [8] and anticancer drugs (reviewed in [9]). One of the genes frequently associated with EMT is the zinc-finger transcriptional repressor Snail (SNAI1) [10]. Snail, together with Slug (SNAI2) and Smuc (SNAI3), comprises the Snail family of transcription factors [11]. Previous studies indicate that both Snail and Slug may contribute to the progression of breast and other types of cancer by the down regulation of E-cadherin (CDH1) and other genes associated with the epithelial phenotype and the up regulation of genes associated with the mesenchymal phenotype (reviewed in $[10,12])$.

In this study, we were interested in characterizing, on a molecular systems level, the role of Snail in breast cancer EMT and the consequence of this transition on the sensitivity of breast cancer cells to a variety of therapeutic treatments. Toward this end, we performed system level analyses of differences in global patterns of gene expression and therapeutic response profiles between two cell lines derived from the well-studied epithelial breast cancer cell line MCF-7 (Michigan Cancer Foundation-7) [13]. MCF-7-Snail is a derivative of MCF-7 that has been stably transfected with a variant (Snail-6SA) of Snail and displays a mesenchymal-like morphology. Snail-6SA is a more stable protein than wild-type Snail and it has been shown to display constitutive activity and ability to induce EMT [14, 15]. MCF-7-Control is a derivative of $M C F-7$ that has been transfected with an empty vector and displays the same epithelial morphology as the parental $M C F-7$ cell line [14].

We report here that MCF-7-Snail cells display significant changes in the expression of several master regulators of
EMT, including various zinc-finger and basic helix-loophelix transcription factors, as well as members of the miR-200 family of microRNAs. While MCF-7-Control cells display molecular profiles characteristic of the luminal A (ER-positive, PR-positive, HER2-negative) breast cancer subtype, MCF-7-Snail cells were found to display molecular profiles characteristic of the aggressive triple-negative (ER-negative, PR-negative, HER2-negative), claudin-low breast cancer subtype. In addition, we found that relative to the MCF-7-Control, MCF-7Snail cells display a higher level of cellular ROS, lower levels of GSH and NF-kB (nuclear factor kappa-light-chain-enhancer of activated $B$ cells) activity, increased sensitivity to ionizing radiation and increased, decreased or no change in sensitivity to several anti-cancer drugs. Our results underscore the complexity of the EMT process in breast cancer cells and its consequence on cancer therapies.

\section{Methods \\ Cell lines}

MCF-7-Snail and MCF-7-Control cells, developed as previously described [14], were kindly provided by Dr. Valerie Odero-Marah (Clark Atlanta University). Transfected MCF-7-Snail and MCF-7-Control cells were selected from several clones to display the highest expression of Snail or the highest phenotypic similarity (doubling time) to the parental MCF-7 cells, respectively. Over-expression of Snail in MCF-7-Snail cells has been demonstrated using the western blot analysis [16]. Cells were routinely maintained in RPMI 1640 medium supplemented with $10 \%$ FBS (Atlanta Biologicals, Lawrenceville, GA), $1 \%$ antibiotic-antimycotic solution (Mediatech-Cellgro, Manassas, VA) and $400 \mu \mathrm{g} / \mathrm{mL}$ G418 (Geneticin, GIBCO) at $37^{\circ} \mathrm{C}$ in a humidified atmosphere with $5 \% \mathrm{CO}_{2}$ and sub-cultured when they reach $\sim 80 \%$ confluence. In all experiments, cells were no more than four passages from the originally received $M C F-7-S n a i l$ and $M C F-7-C o n t r o l$ cells.

\section{Expression analysis by microarray}

MCF-7-Snail and MCF-7-Control cells (three replicates per cell line) were grown in the above-described medium and processed for microarray analysis using the Human Genome U133 Plus 2.0 Array (Affymetrix, Santa Clara, CA, USA). The resulting data were acquired as CEL files and processed with Expression Console software Build 1.2.1.20 (Affymetrix, Santa Clara, CA, USA) using the Affymetrix default analysis setting for PLIER and MAS 5.0 algorithms with annotation file HG-U133 Plus_2, Release 34 from 10/24/2013 (www.affymetrix.com). A detailed description of the microarray experiment and the resulting data are available in the Gene Expression Omnibus repository (GEO, http://www.ncbi.nlm.nih.gov/geo/) under the accession number GSE58252. 


\section{Differential expression analysis}

Expression signals were converted to PLIER+16 and $\log _{2}$-transformed. Probe sets that displayed absent detection calls (MAS5.0 algorithm) across all chips were removed and $\log 2$ PLIER+16 values were used to identify genes differentially expressed between MCF-7-Snail and MCF-7-Control cells using the Significance Analysis of Microarrays (SAM) version 4.01 [17]. Genes were reported as differentially expressed at FDR $=2.12 \%$ and absolute fold change $(F C) \geq 1.5$. Differential gene expression was interpreted in the context of EMT and resistance to anticancer drugs using manually curated lists of 71 genes relevant to EMT and 53 genes relevant to anticancer drug resistance (these genes and their Affymetrix probe set IDs are listed in Additional file 1). The threshold for the expression signal intensities that allows identification of genes as highly likely "not expressed" was calculated by the "funnel-shaped procedure" described by Saviozzi et al. [18] and used to support lack of expression of selected genes (Additional file 2: Figure S1).

\section{Pathway enrichment analysis}

Probesets corresponding to differentially expressed genes were employed for enrichment analysis using the MetaCore suite 6.18 build 65,505 (Thomson Reuters, New York, NY, USA). Briefly, significantly perturbed pathways and process networks were identified by mapping differentially expressed genes onto manually curated GeneGO canonical pathway maps and cell process network models [19].

\section{Interactome analysis}

For each protein from the list of differentially expressed genes between MCF-7-Snail and MCF-7Control cells, one step interaction neighbors from the global human interactome were identified using the MetaCore "interactome by protein function" tool (MetaCore suite 6.18 build 65,505; Thomson Reuters) and the local interactome was built by adding them to the protein interaction network built from genes differentially expressed between MCF-7-Snail and MCF-7-Control cells. Observed connectivity of each protein (network object) from this local interactome was compared to its expected connectivity based on the global human interactome and relative connectivity (connectivity ratio) was calculated to identify over-connected or under-connected network objects. Statistical significance of differences between observed and expected connectivities was evaluated using the hypergeometric test and multiplicity was controlled by the FDR procedure [20]. The list of over-connected network objects at $\mathrm{FDR}=0.01$ was reported.

\section{Transcriptional network building}

To elucidate complex relationships among the regulators of EMT in our dataset, a custom transcriptional network was built using the results of the differential expression analysis, previously reported associations between genes and EMT, as well as previously reported information on transcriptional regulation and influence on expression between selected network objects. Differentially expressed (i) transcription factors that were previously reported as major regulators of EMT, (ii) microRNA-200 family members, and (iii) epithelial or mesenchymal phenotypeassociated genes coding for adherence junctions, tight junctions and intermediate filaments were employed to build the transcriptional network using the knowledgebased system MapEditor (MetaCore suite 6.18 build 65,505; Thomson Reuters). Relative expression data for network objects were color coded (red: up-regulation; blue: down-regulation in MCF-7-Snail relative to MCF-7Control cells) and mapped on the transcriptional network. Network objects (genes) were connected in the network if their transcription regulation relationships were previously documented and included in the MetaCore knowledge base.

\section{Gene Set Enrichment Analysis (GSEA)}

To identify gene sets significantly enriched in a given phenotype (MCF-7-Snail or MCF-7-Control), GSEA [21] was performed on the data processed by PLIER+16 without any pre-filtering of probe sets, using categorical phenotype labels, gene set permutation type and signalto-noise metrics. The following gene sets were employed in the analysis: C2: Curated Gene Sets (4722 gene sets) and C6: Oncogenic Signatures (189 gene sets) from the Molecular Signatures Database (http://www.broadinstitute.org/gsea/msigdb/collections.jsp).

In all enrichment analyses, the statistical significance of enrichment was evaluated using $p$-values calculated based on hypergeometric distribution and corrected for multiplicity using the false discovery rate (FDR) procedure. Unless stated otherwise, pathways, process networks or gene sets were considered to be significantly enriched, if their q-values were $\leq$ FDR threshold, for which the expected number of false positive entities was $\leq 1$.

\section{MicroRNA expression analysis by qPCR}

Relative expression of miRNA-429, miR-200a, miR-200b and miR-141 in MCF-7-Snail vs MCF-7-Control cells was determined by qPCR using specific TaqMan miRNA assays for miRNA-429, miR-200a, miR-200b and miR141, and non-coding small nuclear RNA RNU6B as an endogenous reference (Applied Biosystems/Life Technologies, Carlsbad, CA). Total cell RNA was isolated using the mirVana miRNA Isolation Kit (Ambion, Foster City, CA, USA) and cDNAs were prepared using the 
miRNA-specific stem-loop RT primers and TaqMan MicroRNA Reverse Transcription Kit following the manufacturer's recommendation. Thereafter, cDNA was amplified using the TaqMan Universal Master Mix II with UNG in the CFX96 Real Time PCR Detection System (BioRad, Hercules, CA) following the manufacturer's recommendation. Expressions of individual miRNAs in MCF-7-Snail relative to MCF-7-Control cells was calculated from the threshold cycles using the REST 2009 Software (Qiagen, Valencia, CA, USA) [22] and expressed as means, and the $95 \%$ confidence intervals calculated by bootstrapping technique without normality or symmetrical distribution assumptions. $P$-values determined by a randomization test represent the probability that the observed difference in expression between MCF-7-Snail and MCF-7-Control cells is due to chance.

\section{Determination of radiation sensitivity}

One hundred thousand cells were plated in $2.5 \mathrm{~mL}$ of RPMI 1640 medium supplemented with $10 \%$ FBS in $35 \mathrm{~mm}$ tissue culture dishes (Corning Incorporated, Corning, NY, USA). After $24 \mathrm{~h}$, the cultures were irradiated in an RS-2000 X-ray irradiator ( $\operatorname{Rad}$ Source Technologies, Suwanee, GA) at $160 \mathrm{kV}$ and $25 \mathrm{~mA}$ on an aluminum specimen shelf four at dose rate $~ 311 \mathrm{cGy} /$ min and single dose levels 2 Gy (39 s), 4 Gy (77 s) and 8 Gy (154 s). Control medium was irradiated at 4 Gy. After the irradiation, cells were allowed to grow for $72 \mathrm{~h}$ at $37{ }^{\circ} \mathrm{C}$ in a humidified atmosphere with $5 \% \mathrm{CO}_{2}$. For quantification of viable cells, $200 \mu \mathrm{L}$ of Tox -8 reagent were added to each dish and incubated for $2.5 \mathrm{~h}$ at $37^{\circ} \mathrm{C}$ in a humidified atmosphere with $5 \% \mathrm{CO}_{2}$. Thereafter, the specimens were transferred to a 96-well plate (200 $\mu \mathrm{L} /$ well) and viable cells were quantified via fluorescence at $560 \mathrm{~nm}$ excitation and $590 \mathrm{~nm}$ emission. The results were expressed as \% of non-irradiated control.

\section{Determination of cell cycle distribution}

Cells plated in parallel with cells used in the radiation sensitivity experiment were cultured for $24 \mathrm{~h}$, harvested by trypsinization, fixed and stained for DNA analysis by flow cytometry as previously described [23]. Cell cycle distribution was determined by deconvolution of DNA content histograms, after discrimination of doublets and other cellular aggregates by FlowJo 7.6.5 software (Tree Star, Inc., Ashland, OR, USA) using the Dean-Jet-Fox Model. For each cell line, the flow cytometry DNA analysis was performed on three independent cell cultures and the results are presented as means from these three experiments.

\section{Determination of intracellular level of ROS}

MCF-7-Snail and MCF-7-Control cells in the RPMI-1640 medium supplemented with $10 \%$ FBS $(20,000$ cells $/ \mathrm{mL})$ were plated into 96-well black-walled plate $(100 \mu \mathrm{L} /$ well $)$ and incubated for $48 \mathrm{~h}$ at $37^{\circ} \mathrm{C}$ in a humidified atmosphere with $5 \% \mathrm{CO}_{2}$. Thereafter, the medium was removed and $10 \mu \mathrm{M}$ solution of $2^{\prime}, 7^{\prime}$-dichlorodihydrofluorescein diacetate (H2DCF-DA, Molecular Probes, Inc., Eugene, OR) in PBS was added to each well (100 $\mu \mathrm{L} /$ well). H2DCF-DA is a general oxidative stress indicator that can detect several types of ROS including hydrogen peroxide, hydroxyl radicals and peroxynitrite [24]. Cells were incubated for additional $30 \mathrm{~min}$ at $37^{\circ} \mathrm{C}$ in a humidified atmosphere with $5 \% \mathrm{CO} 2$ and the fluorescence of the ROS-sensitive dye was measured by a Synergy 4 microplate reader (Biotek, Winooski, VT) with filter set 485/20 nm (excitation), 528/20 nm (emission) and $510 \mathrm{~nm}$ full-size mirror. Fluorescence intensity corresponding to the ROS signal was normalized to the quantity of viable cells per well as determined by TOX-8 assay and expressed as mean $\pm \mathrm{SD}$.

\section{Determination of cellular glutathione}

MCF-7-Snail and MCF-7-Control cells in DMEM medium (glutathione-free) supplemented with $10 \%$ FBS $(20,000$ cells $/ \mathrm{mL})$ were plated onto the tissue culturetreated 96-well white-walled plate $(100 \mu \mathrm{L} /$ well $)$ and incubated for $48 \mathrm{~h}$ at $37^{\circ} \mathrm{C}$ in a humidified atmosphere with $5 \% \mathrm{CO}_{2}$.

Reduced glutathione (GSH) and total cellular glutathione (GSH+GSSG) in MCF-7-Snail and MCF-7-Control cells were quantified using the GSH-Glo Glutathione Assay (Promega, Madison, WI, USA). In this assay, the luciferin derivative Luc-NT is converted in the presence of GSH and glutathione S-transferase (GST) to luciferin that generates a luminescent signal in a coupled reaction catalyzed by firefly luciferase. The assay was performed following the manufacturer's instructions for adherent cell cultures.

Total cellular glutathione was determined after reduction of GSSG to GSH with tris(2-carboxyethyl) phosphine (TCEP, final concentration $1 \mathrm{mM}$ ). The luminescence signal after subtraction of blanks (net RLU) was normalized to the number of viable cells determined by resazurinbased cell viability assay TOX-8 (Sigma-Aldrich, St. Louis, $\mathrm{MO})$. All experiments were performed in triplicate.

\section{Determination of the level of nuclear NF-KB}

MCF-7-Snail and MCF-7-Control cells each in three replicated cultures were grown in full growth medium to $\sim 80 \%$ confluence, harvested by scraping and processed to obtain nuclear protein extracts using the CelLytic NuCLEAR Extraction Kit (Sigma-Aldrich) following the manufacturer's protocol. Protein concentration in nuclear extracts was determined using the Pierce $660 \mathrm{~nm}$ Protein Assay (Thermo Scientific, Rockford, IL). NF-kB (p50 subunit) was determined in nuclear protein extracts 
by an ELISA-based assay using the NF- $\mathrm{kB}$ (human p50) Transcription Factor Assay Kit (Cayman Chemical Company, Ann Arbor, MI, USA) in 96-well assay format following the manufacturer's protocol. After developing plates, the stop solution was added and signals corresponding to the p50 protein levels were read as $A_{450}-A_{570}$. Concentration of nuclear NF- $\mathrm{kB}$ was expressed as $A_{450}-A_{570}$ corrected for non-specific binding signal and normalized to protein concentration in nuclear extracts. The results were expressed as means \pm SDs.

\section{Determination of drug sensitivity}

Sensitivity of MCF-7-Snail and MCF-7-Control cells to the cytotoxic effects of selected conventional anticancer drugs was evaluated using the resazurin-based in vitro toxicology assay kit TOX-8 (Sigma-Aldrich) as previously described [23]. Aliquots of cell suspensions (100 $\mu \mathrm{L} /$ well) were plated onto 96-well black-walled plates at 30,000 cells/mL in RPMI 1640 medium supplemented with $10 \%$ FBS, $1 \%$ antibiotic-antimycotic solution and $400 \mu \mathrm{g} / \mathrm{mL}$ G418. Tested compounds were diluted from the following stock solutions: vincristine (VCR) - $0.4 \mathrm{mM}$ in DMSO; doxorubicin (DOX) - $2 \mathrm{mM}$ in DMSO; methotrexate (MTX) - $1 \mathrm{mM}$ in DMSO; gemcitabine (GEM) - $10 \mathrm{mM}$ in $\mathrm{H}_{2} \mathrm{O}$; mitomycin $\mathrm{C}$ (MMC) - $10 \mathrm{mM}$ in DMSO; 5-fluorouracil (5-FU) $16.5 \mathrm{mM}$ in $\mathrm{H}_{2} \mathrm{O}$; cisplatin (CPT) $-1.7 \mathrm{mM}$ in $0.9 \%$ $\mathrm{NaCl} / \mathrm{H}_{2} \mathrm{O}$. Tested compounds dissolved in growth medium at a concentration twice the desired final concentration were added in quadruplicates at $100 \mu \mathrm{L}$ volumes per well. Incubation of cells with drugs or control medium proceeded for $72 \mathrm{~h}$. After that, $20 \mu \mathrm{L}$ of the TOX-8 reagent were added to each well and incubated for the next $3 \mathrm{~h}$. The increase of fluorescence was measured at a wavelength of $590 \mathrm{~nm}$ using an excitation wavelength of $560 \mathrm{~nm}$. The emission of control wells (no drug treatment) after the subtraction of a blank was taken as $100 \%$ and the results for treatments were expressed as a percentage of the control. The experiment was performed four times and GI50 values (concentrations of tested agents that inhibited growth of cell cultures after 72-h incubation to $50 \%$ of the untreated control) were determined by non-linear regression of log-transformed data using a normalized responsevariable slope model (GraphPad Prism 5.01; GraphPad Software, Inc.) and expressed as mean \pm SD.

\section{Statistical analyses}

Unless stated otherwise, the statistical significance of differences between means of continuous data was evaluated by Welch-corrected t-test and considered significant for two-tailed $p$-values $<0.05$. In the analysis of microarray data, multiplicity of statistical tests was corrected by the FDR approach and the discoveries were considered significant if their rank and q-value would allow not more than one false discovery. When multiple comparisons were performed in other experiments, $p$-values were adjusted by the Šidák-Holm approach and considered significant for $p_{\text {adj }}<0.05$. Unless stated otherwise, results of continuous variables were expressed as means \pm SD.

\section{Results}

MCF-7-Snail cells display morphological and molecular changes characteristic of EMT

MCF-7-Snail cells display an elongated morphology characteristic of mesenchymal-like breast cancer cells (Fig. 1a-b). In contrast MCF-7-Control cells, like their parental MCF-7 cells, display the classic "cobble-stone" morphology characteristic of breast cancer epithelial cells (Fig. 1c-d). Consistent with these morphological differences, MCF-7-Snail and MCF-7-Control cells are remarkably different in their respective patterns of gene expression (Additional file 2: Figure S2).

Among 38,226 probe sets included in the differential expression analysis, over 12,000 probe sets corresponding to 7602 genes were found to display statistically significant differences in expression (4242 up-regulated; 3291 downregulated; 69 discordant) between $M C F-7-S n a i l$ and $M C F$ 7-Control cells (FDR $=2.12 \%$ and $|\mathrm{FC}| \geq 1.5$ (Additional file 2: Figure S3, Additional files 3 and 4). Among the genes significantly differentially expressed are many that have been previously implicated in EMT, including transcription factors Slug, Zeb1, Zeb2, Twist1 [25] and TCF4 [26] (Fig. 2). Among the differentially expressed genes 69 genes displayed discordant expression with some probe sets detecting their up regulation and other probe sets detecting down regulation (Additional file 4). The overexpression of SNAI1 (Snail) and SNAI2 (Slug) genes in MCF-7-Snail relative to MCF-7-Control cells was confirmed by qPCR (Additional file 2: Figure $\mathrm{S} 4$ and Additional file 2: Method S1. We have previously reported the up-regulation of mesenchymal markers $\mathrm{CDH} 2$ and VIM and down-regulation of epithelial marker CDH1 in MCF-7-Snail cells by RT-PCR [27].

\section{The miR-200 family of microRNAs are significantly down- regulated in MCF-7-Snail cells}

The regulatory role of microRNAs in EMT is an area of growing interest for both developmental and cancer biologists [28]. Members of the miR-200 family of microRNAs are of particular interest because they have been previously shown to target genes that play central roles in EMT (e.g., Zeb1, Zeb2, Slug) [29, 30]. In addition, more recent studies have demonstrated that miR-429 and other members of the miR-200 family are down regulated in ovarian cancer mesenchymal-like cells and that ectopic over-expression of these miRNAs in 


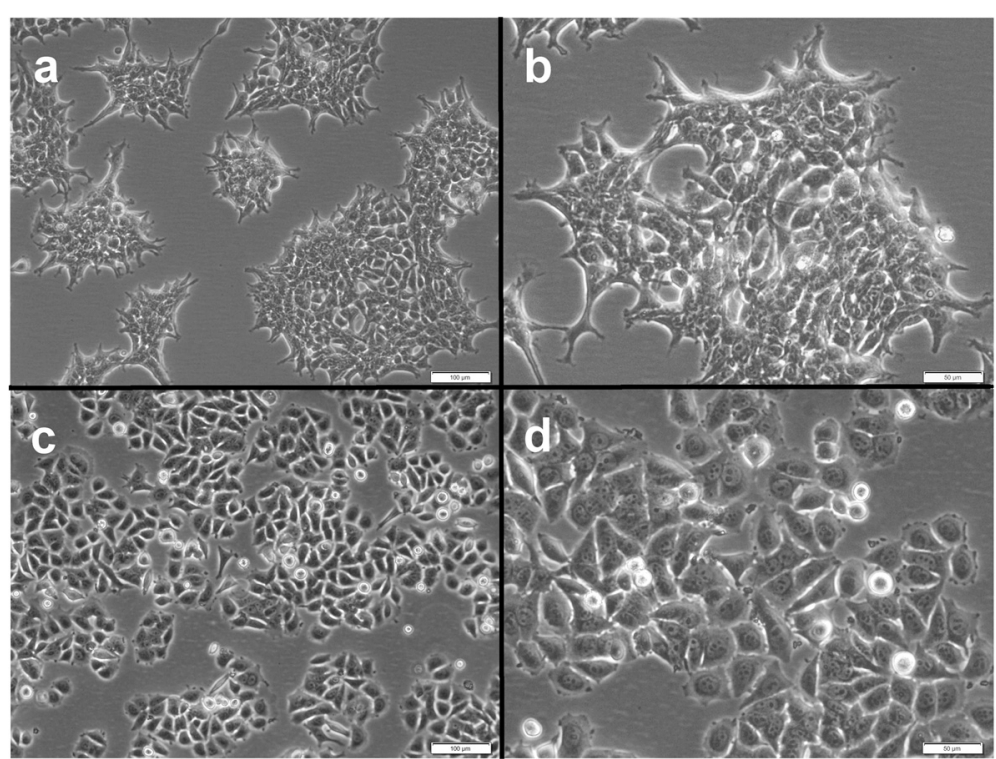

Fig. 1 Brightfield (phase contrast) micrographs of MCF-7-Snail and MCF-7-Control cells. Shown are MCF-7-Snail (a, b) and MCF-7 Control cells (c, d). Magnification: $100 \times(\mathbf{a}, \mathbf{c})$ or $200 \times(\mathbf{b}, \mathbf{d})$. Scale bars: $100 \mu \mathrm{m},(\mathbf{a}, \mathbf{c})$ and $50 \mu \mathrm{m}(\mathbf{b}, \mathbf{d})$

these cells is sufficient to induce mesenchymal-toepithelial transition (MET) [31-33]. In light of these findings and because Snail-induced repression of miR200 family miRNAs has recently been implicated with EMT in embryonic stem cells (ESC) [34], we examined levels of miR-200 members in MCF-7-Snail cells relative to controls.
The results of comparative qPCR expression analyses of four miRNA-200 family members in MCF-7-Snail and MCF-7-Control cells indicate that levels of miR-200 family microRNAs are consistently and significantly reduced in the mesenchymal-like MCF-7-Snail cells (Fig. 3). Since a number of EMT associated genes are known or predicted targets of miR-200 family members

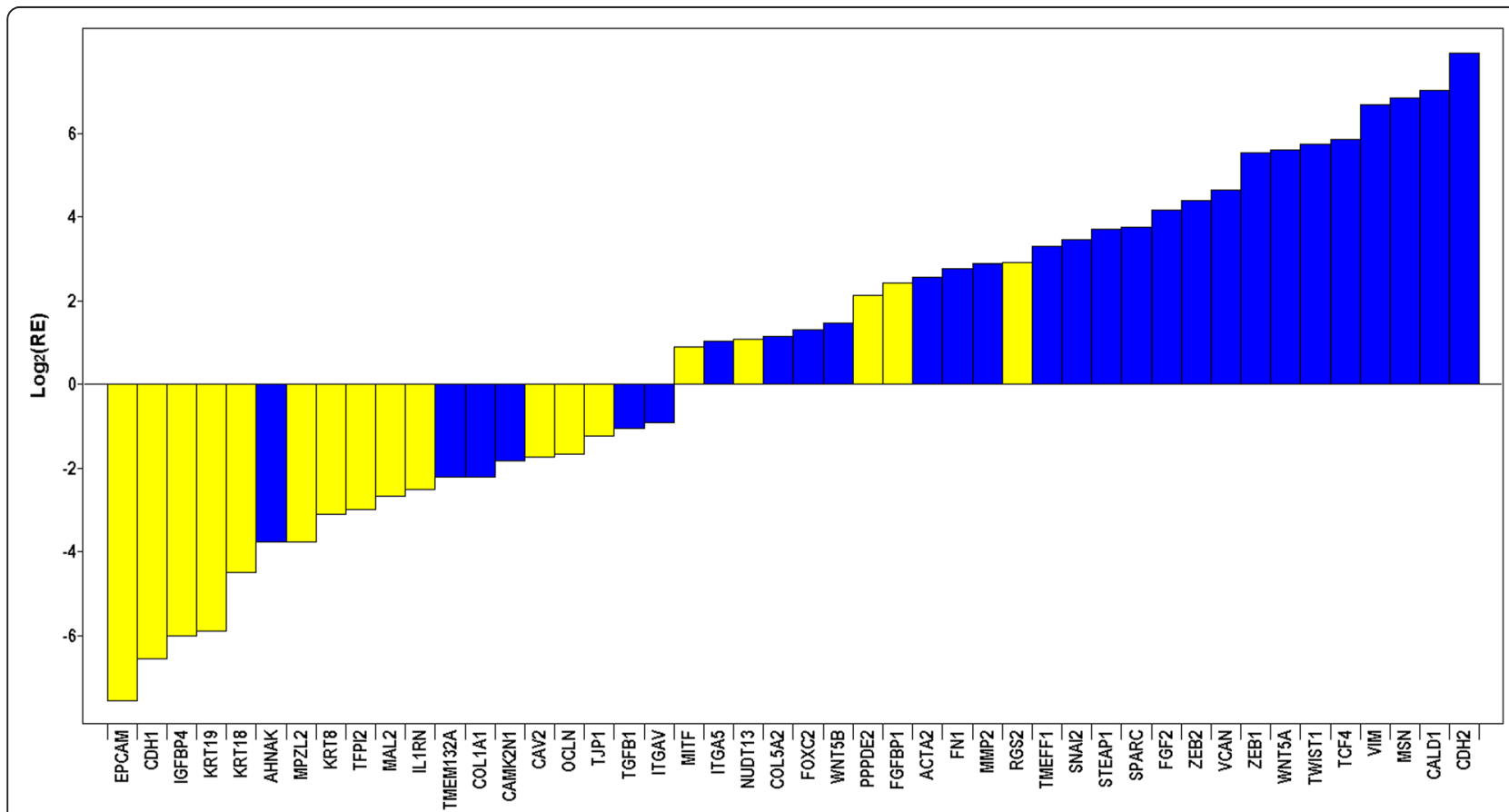

Fig. 2 Relative expression of a subset of the 71 EMT-related genes in MCF-7-Snail vs MCF-7-Control cells. Results shown in log2 scale (from microarray data). Color-coding: Yellow = epithelial phenotype-associated genes; blue = mesenchymal phenotype-associated genes 


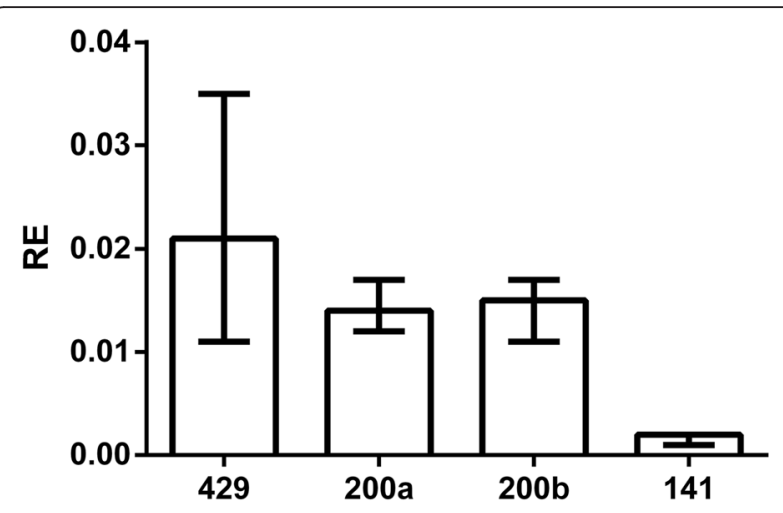

Fig. 3 Relative expression of miRNA 200 family members in MCF-7-Snail vs MCF-7 Control cells. Relative expression (RE) determined by qPCR. Error bars: $95 \% \mathrm{Cl}$ ( $N=4$ replicates). $P$-values from randomization test: miR-429 $(p=0.008)$, miR-200a $(p=0.016), \operatorname{miR}-200 \mathrm{~b}(0.022), \operatorname{miR}-141 \quad(p=0.015)$
(Fig. 4), these findings suggest that down regulation of members of the miR-200 family of microRNAs may contribute to the regulatory changes associated with EMT in MCF-7-Snail cells.

\section{Systems analysis provides evidence of a complex regulatory interplay between EMT-associated genes and miR-200 family miRNAs in MCF-7-Snail cells}

Transcriptional network analysis of genes and miR-200 miRNAs differentially expressed between MCF-7-Snail and MCF-7-Control cells suggests a complex regulatory relationship among EMT-associated transcription factors, miR-200 family members and various cytoskeletal and junction proteins previously associated with the epithalial/ mesenchymal phenotype (Fig. 4).

Pathway Enrichment Analysis of the 7634 network objects that were recognized by MetaCore suite among

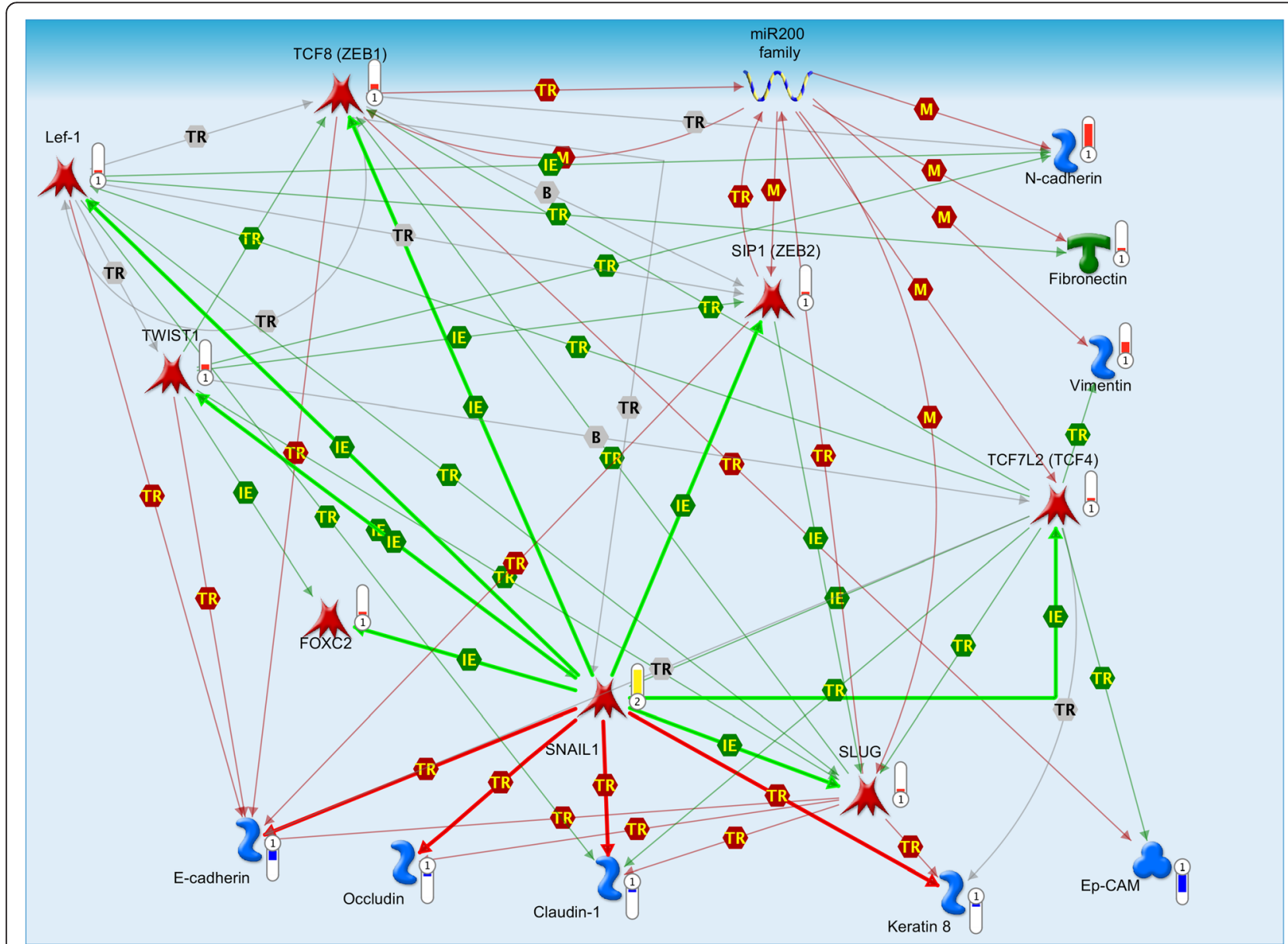

Fig. 4 Complex regulatory interplay among transcription factors, miRNA 200 family members and E/M-phenotype related genes. Map created from genes differentially expressed between MCF-7-Snail and MCF-7-Control cells using MapEditor (Thomson Reuters, New York, NY, USA) to connect network objects based on previously reported associations. Legend for edges: TR transcriptional regulation, IE influence on expression, M microRNA binding. Green edge - activation; red edge repression. Edges originating or ending at SNAl1 are depicted as thick lines. Thermometers: red = network object up-regulated in MCF-7-Snail cells; blue = network object down-regulated in MCF-7-Snail cells; yellow = network object identified as over-connected to the list of differentially expressed genes. For more details on legend https://portal.genego.com/legends/ 
7602 differentially expressed genes between MCF-7Snail and MCF-Control cells, identified 18 significantly enriched pathways for both up- and down-regulated genes (Table 1, FDR $=0.06089$ ). Likewise, six significantly enriched pathways were identified for up-regulated genes only (Additional file 2: Table S1, FDR $=0.1677$ ) and 69 pathways for down-regulated genes only (Additional file 2: Table S2, FDR =0.01514). Mapping up- and downregulated genes onto GeneGO Process Network Maps identified 30 significantly enriched networks (Table 2, $\mathrm{FDR}=0.03104)$. As expected, the enriched pathways and networks include those related to EMT (e.g., Fig. 5, Tables 1 and 2). Additionally implicated were other related cellular processes including the Wnt-signaling, Hedgehog signaling, estrogen receptor-mediated signaling, $\mathrm{NOTCH}-$ signaling, ERBB-signaling, the endoplasmic reticulum stress pathway, and reactive oxygen species (ROS)-associated processes (Tables 1 and 2).

To further explore genes differentially expressed between MCF-7-Snail and MCF-7-Control cells, we examined their paired (binary) protein interactions with those in the MetaCore human protein interaction network [20]. This interactome analysis identified 164 significantly over-connected, but no significantly under-connected human interactome proteins (Additional file 5). The list of over-connected proteins includes: (i) Snail, Slug and Twist1 consistent with their previously recognized role in EMT [25]; (ii) GSK3B, RYK, $\beta$-catenin (CTNNB1) and TCF7L2 (TCF4) consistent with a role in the Wnt signaling pathway in Snail-induced
EMT [10]; (iii) ESR1, PGR (PR) and androgen receptor suggesting a role of the sex-hormone-receptor-mediated signaling pathway; (iv) cancer-associated transcription factors p53 (TP53) and c-Myc (MYC), and (iv) the pluripotency-associated transcription factors KLF-4, Oct3/ 4, Nanog, Sox2 [35, 36].

We next focused on transcription factor sub-networks represented among genes significantly differentially expressed between MCF-7-Snail and MCF-7-Control cells. This analysis identified 31 transcription factorcentered networks (Additional file 6) confirming a likely role of several transcription factors previously implicated in EMT (MYC, Oct3/4, ESR1, p53, Nanog, Sox2 and TCF-4), in addition to others (CREB1, SP1, NF-kB, and ETS1). For example, among the 294 genes differentially expressed between MCF-7-Snail and MCF-7-Control cells known to be transcriptionally activated by MYC, $240(\sim 82 \%)$ were up regulated in MCF-7-Snail cells (Additional file 7). Of the 162 genes differentially expressed between MCF-7-Snail and MCF-7-Control cells known be transcriptionally repressed by MYC, 107 ( $66 \%$ ) were found to be down regulated in MCF-7-Snail cells (Additional file 7). These results suggest a significant role and up-regulated activity of MYC in Snail-induced EMT in breast cancer.

\section{MCF-7-Snail cells display molecular profiles characteristic} of the triple-negative breast cancer subtype

Estrogen receptor 1 (ESR1), progesterone receptor (PGR) and $E R B B 2$ genes were found to be significantly down-

Table 1 GeneGO pathway maps significantly enriched for both up- and down-regulated genes in MCF-7-Snail vs MCF-7-Control cells $(F D R=0.06089) ; P / T$ - differentially expressed genes mapped to a given map/total number of genes in a map

\begin{tabular}{|c|c|c|c|c|}
\hline \# & Pathway map & $p$-value & FDR & $\mathrm{P} / \mathrm{T}$ \\
\hline 1 & Chemotaxis_C5a-induced chemotaxis & $6.298 \mathrm{E}-05$ & 3.136E-02 & $21 / 27$ \\
\hline 2 & $\mathrm{ENaC}$ regulation in normal and CF airways & 7.539E-05 & 3.136E-02 & $26 / 36$ \\
\hline 3 & Development_TGF-beta-dependent induction of EMT via SMADs & 1.394E-04 & 3.865E-02 & $25 / 35$ \\
\hline 4 & Development_Thromboxane A2 signaling pathway & 2.847E-04 & 5.199E-02 & $25 / 36$ \\
\hline 5 & Muscle contraction_Relaxin signaling pathway & $3.125 \mathrm{E}-04$ & 5.199E-02 & $26 / 38$ \\
\hline 6 & $\mathrm{Ca}(2+)$-dependent NF-AT signaling in cardiac hypertrophy & $5.485 \mathrm{E}-04$ & 5.627E-02 & $25 / 37$ \\
\hline 7 & Main growth factor signaling cascades in multiple myeloma cells & 5.485E-04 & 5.627E-02 & $25 / 37$ \\
\hline 8 & Cytoskeleton remodeling_RalA regulation pathway & 5.733E-04 & 5.627E-02 & $19 / 26$ \\
\hline 9 & Regulation of CFTR activity (normal and CF) & $6.448 \mathrm{E}-04$ & 5.627E-02 & $28 / 43$ \\
\hline 10 & Signal transduction_Calcium signaling & 8.247E-04 & 5.627E-02 & $22 / 32$ \\
\hline 11 & Apoptosis and survival_HTR1A signaling & $1.003 \mathrm{E}-03$ & 5.627E-02 & $25 / 38$ \\
\hline 12 & Development_A1 receptor signaling & 1.003E-03 & 5.627E-02 & $25 / 38$ \\
\hline 13 & Transcription_CREB pathway & $1.045 \mathrm{E}-03$ & 5.627E-02 & $26 / 40$ \\
\hline 14 & Transport_Clathrin-coated vesicle cycle & 1.054E-03 & 5.627E-02 & $40 / 68$ \\
\hline 15 & PTMs in IL-17-induced CIKS-independent signaling pathways & 1.079E-03 & 5.627E-02 & $27 / 42$ \\
\hline 16 & Signal transduction_Activation of PKC via G-Protein coupled receptor & 1.107E-03 & 5.627E-02 & $28 / 44$ \\
\hline 17 & Apoptosis and survival_Endoplasmic reticulum stress response pathway & 1.150E-03 & 5.627E-02 & $31 / 50$ \\
\hline 18 & Development_Hedgehog and PTH signaling pathways in bone and cartilage development & $1.345 \mathrm{E}-03$ & 6.089E-02 & $20 / 29$ \\
\hline
\end{tabular}


Table 2 GeneGO Process Networks significantly enriched for both up- and down-regulated genes in MCF-7-Snail vs MCF-7-Control cells (FDR $=0.03104)$. $\mathrm{P} / \mathrm{T}$ - differentially expressed genes mapped to a given map/total number of genes in a map

\begin{tabular}{|c|c|c|c|c|}
\hline \# & Network & $p$-value & FDR & $\mathrm{P} / \mathrm{T}$ \\
\hline 1 & Signal transduction_WNT signaling & $1.774 \mathrm{E}-07$ & $2.622 \mathrm{E}-05$ & $100 / 170$ \\
\hline 2 & Cell adhesion_Cell junctions & $3.278 \mathrm{E}-07$ & 2.622E-05 & $89 / 149$ \\
\hline 3 & Cytoskeleton_Regulation of cytoskeleton rearrangement & $5.064 \mathrm{E}-07$ & 2.701E-05 & $104 / 181$ \\
\hline 4 & Cell adhesion_Cadherins & 1.194E-06 & 4.777E-05 & $100 / 175$ \\
\hline 5 & Cytoskeleton_Actin filaments & $3.552 \mathrm{E}-06$ & 1.137E-04 & $99 / 176$ \\
\hline 6 & Development_Hedgehog signaling & 1.016E-05 & $2.598 \mathrm{E}-04$ & $129 / 244$ \\
\hline 7 & Reproduction_FSH-beta signaling pathway & 1.136E-05 & $2.598 \mathrm{E}-04$ & $86 / 152$ \\
\hline 8 & Development_Neurogenesis_Axonal guidance & 4.544E-05 & $9.088 \mathrm{E}-04$ & $115 / 219$ \\
\hline 9 & Signal transduction_Androgen receptor nuclear signaling & $5.687 \mathrm{E}-05$ & 9.838E-04 & $70 / 123$ \\
\hline 10 & Development_Regulation of angiogenesis & $6.148 \mathrm{E}-05$ & $9.838 \mathrm{E}-04$ & $109 / 207$ \\
\hline 11 & Cell adhesion_Attractive and repulsive receptors & 1.134E-04 & 1.649E-03 & $91 / 170$ \\
\hline 12 & Development_Neurogenesis_Synaptogenesis & $6.650 \mathrm{E}-04$ & 7.983E-03 & $92 / 179$ \\
\hline 13 & Cell cycle_G1-S Growth factor regulation & $6.820 \mathrm{E}-04$ & 7.983E-03 & $96 / 188$ \\
\hline 14 & Development_Ossification and bone remodeling & $7.539 \mathrm{E}-04$ & 7.983E-03 & $80 / 153$ \\
\hline 15 & Signal transduction_ESR1-nuclear pathway & $8.718 \mathrm{E}-04$ & 7.983E-03 & $104 / 207$ \\
\hline 16 & Development_EMT_Regulation of epithelial-to-mesenchymal transition & $8.718 \mathrm{E}-04$ & 7.983E-03 & $104 / 207$ \\
\hline 17 & Signal Transduction_Cholecystokinin signaling & $8.781 \mathrm{E}-04$ & 7.983E-03 & $52 / 93$ \\
\hline 18 & Signal transduction_ERBB-family signaling & 8.981E-04 & 7.983E-03 & $40 / 68$ \\
\hline 19 & Muscle contraction_Relaxin signaling & $2.135 \mathrm{E}-03$ & 1.798E-02 & $37 / 64$ \\
\hline 20 & Apoptosis_Endoplasmic reticulum stress pathway & $2.366 \mathrm{E}-03$ & 1.819E-02 & $44 / 79$ \\
\hline 21 & Development_Neurogenesis in general & 2.387E-03 & 1.819E-02 & $93 / 187$ \\
\hline 22 & Neurophysiological process_Circadian rhythm & $2.520 \mathrm{E}-03$ & 1.833E-02 & $30 / 50$ \\
\hline 23 & Cardiac development_FGF_ErbB signaling & $2.858 \mathrm{E}-03$ & 1.988E-02 & $64 / 123$ \\
\hline 24 & Cardiac development_Wnt_beta-catenin, Notch, VEGF, IP3 and integrin signaling & 3.396E-03 & 2.181E-02 & $70 / 137$ \\
\hline 25 & Signal transduction_ESR1-membrane pathway & $3.425 \mathrm{E}-03$ & 2.181E-02 & $43 / 78$ \\
\hline 26 & Cardiac development_Role of NADPH oxidase and ROS & $3.669 \mathrm{E}-03$ & 2.181E-02 & $64 / 124$ \\
\hline 27 & Reproduction_Gonadotropin regulation & $3.680 \mathrm{E}-03$ & 2.181E-02 & $81 / 162$ \\
\hline 28 & Signal transduction_NOTCH signaling & 4.606E-03 & 2.629E-02 & $109 / 227$ \\
\hline 29 & Signal transduction_Androgen receptor signaling cross-talk & $4.766 \mathrm{E}-03$ & 2.629E-02 & $35 / 62$ \\
\hline 30 & Reproduction_Male sex differentiation & 5.820E-03 & 3.104E-02 & $111 / 233$ \\
\hline
\end{tabular}

regulated in MCF-7-Snail relative to MCF-Control cells (Fig. 6a). In addition, the intensities of ESR1 and PGR transcripts were below computed threshold levels, indicating that these genes are not significantly expressed in MCF-7-Snail cells (Additional file 2: Figure S1B).

Further evidence of the involvement of ESR1 in the molecular changes underlying the phenotypic differences between MCF-7-Snail and MCF-7-Control cells, is the observation that ESR1 is significantly overconnected with genes differentially expressed between the two cell lines (Additional file 5). In addition, of the 262 genes differentially expressed between MCF-7Snail and MCF-7-Control cells known to be transcriptionally activated by ESR1, $172(\sim 66 \%)$ were found to be down regulated in MCF-7-Snail cells (Additional file 8). Collectively, these findings consistently indicate that ESR1-mediated signaling is significantly reduced in MCF-7-Snail relative to MCF-Control cells and we have confirmed the down-regulation of ESR1 in $M C F$ 7-Snail cells by qPCR (Additional file 2: Figure S5a and Additional file 2: Method S2).

Although the expression intensity of the ERBB2 gene that encodes HER-2/neu protein appears to exceed the calculated expression threshold (Additional file 2: Figure S1B), we conclude that the ERBB2 gene is not significantly expressed in MCF-7-Snail cells for the following two reasons: (i) the probe set that detected ERBB2 expression in our dataset (216836_s_at) is not specific and may also detect other transcripts, and (ii) differential expression analysis identified the $E R B B 2$ gene as down regulated upon 


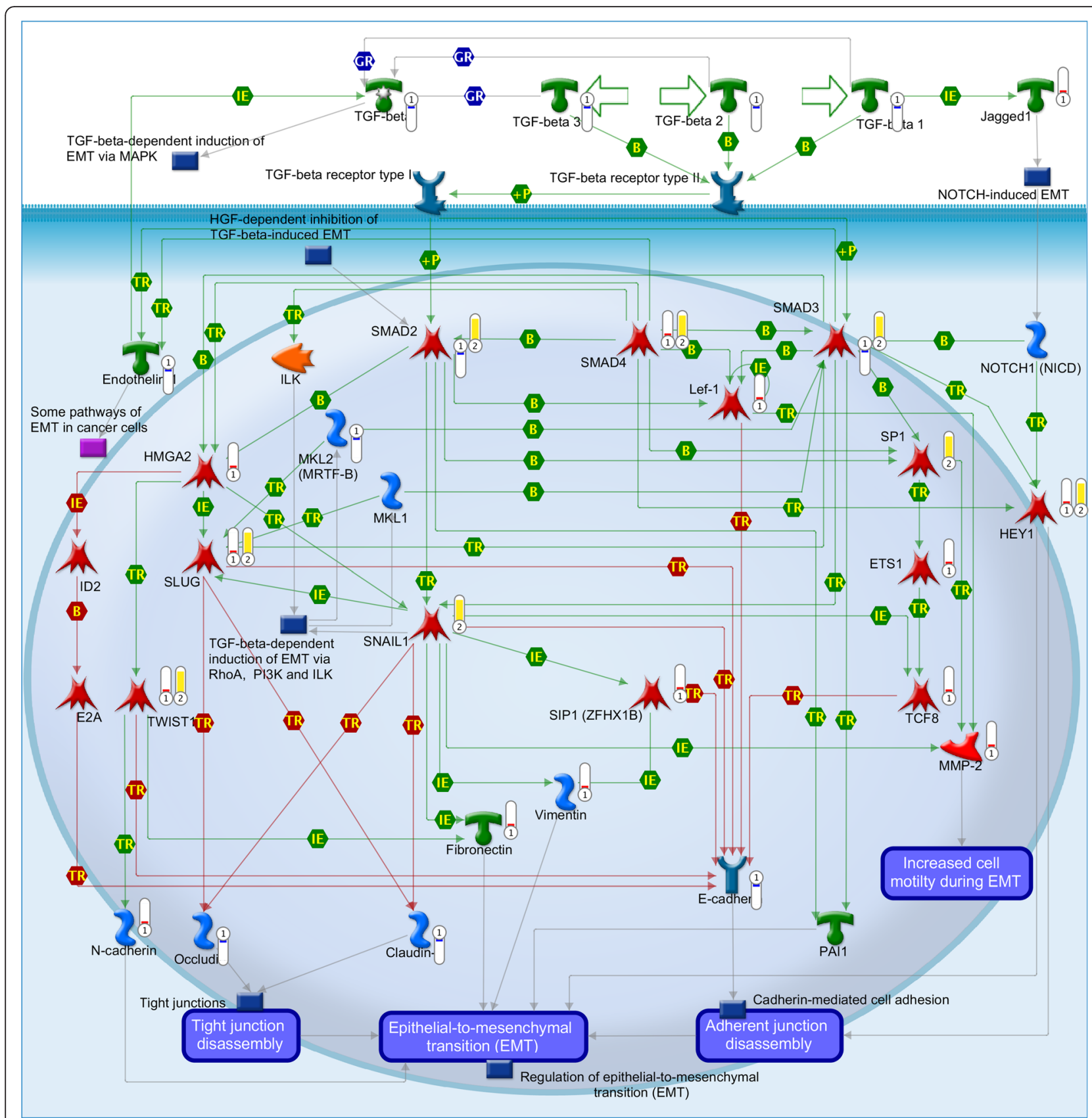

Fig. 5 GeneGO pathway map "Development_TGF-beta-dependent induction of EMT via SMADs" is significantly enriched for genes differentially expressed between MCF-7-Snail and MCF-7-Control cells. Thermometers: red = object up-regulated in MCF-7-Snail cells; blue = object down-regulated in MCF-7-Snail cells; yellow = network object identified as over-connected to the list of differentially expressed genes. For more details on legend see https://portal.genego.com/legends/MetaCoreQuickReferenceGuide.pdf

ectopic expression of Snail in MCF-7 cells, which are known to be HER-2/neu negative [37]. This conclusion is further supported by the quantification of total HER-2/neu protein in MCF-7-Snail and MCF-7-Control cells using the ELISA (Additional file 2: Figure S6 and Additional file 2: Method S3).

Taken together our results indicate that while MCF-7Control cells display molecular profiles characteristic of the luminal A subtype of breast cancer (ER-positive, PRpositive and HER-2/neu-negative) [37, 38], MCF-7-Snail have acquired profiles characteristic of the triple-negative (ER-negative, PR-negative, HER-2/neu-negative), breast cancer subtype.

Gene Set Enrichment Analysis (GSEA) further supports this conclusion in that the enrichment of gene sets previously associated with the ductal-invasive, non-luminal, 


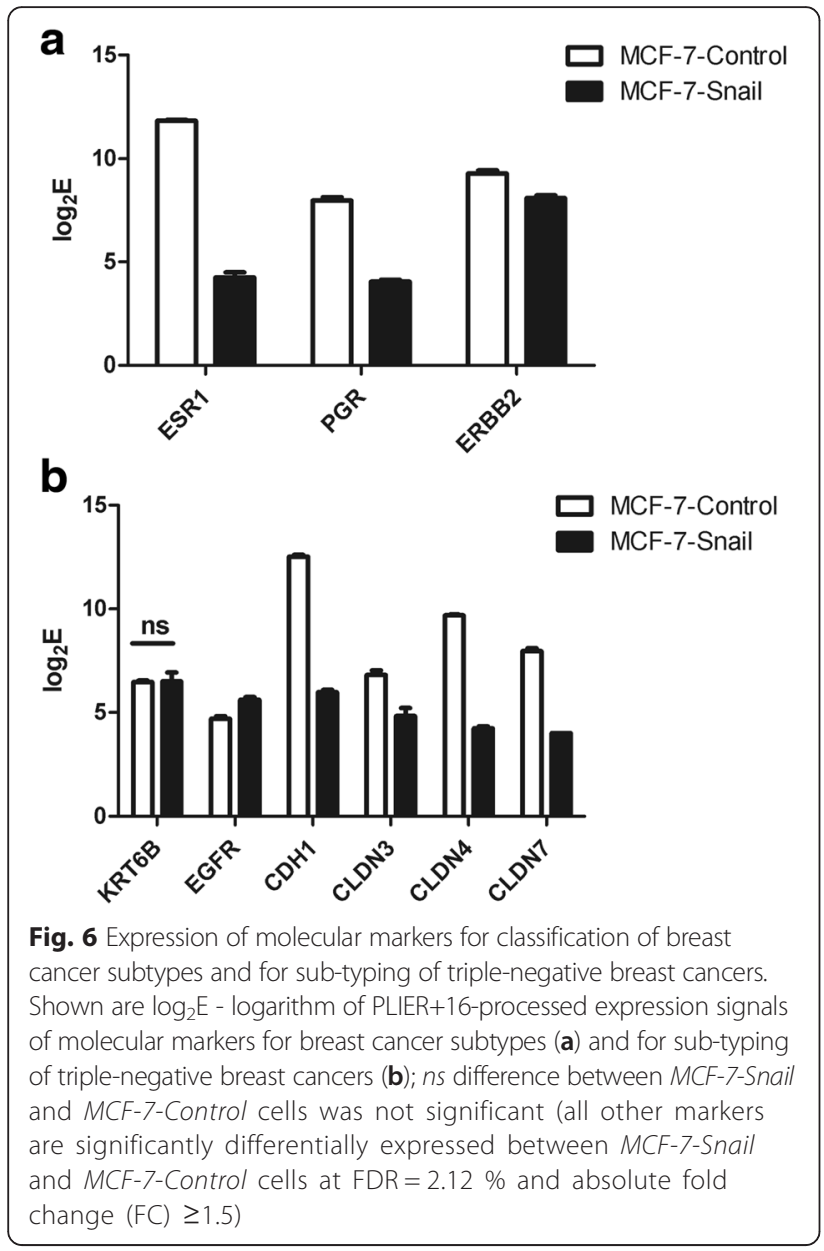

mesenchymal and/or metaplastic phenotype (e.g., activation of KRAS, LEF1, EGFR and suppression of PTEN functions) are also significantly enriched in MCF-7-Snail cells. Conversely, GSEA of MCF-7-Control cells demonstrated enrichment of gene sets previously associated with the estrogen receptor positive, luminal type, and epithelial differentiated phenotype (Additional file 9).

Triple-negative breast cancers have been sub-classified into specific molecular subtypes that include basal-like breast cancers (CK5/6-positive and/or EGFR-positive) [39] and claudin-low breast cancers exhibiting low expression of the $C D H 1$ and claudin 3,4 and 7 genes [40]. Cytokeratins 5 and 6 were not found among genes differentially expressed between MCF-7-Snail and MCF7-Control cells. Consistent with the previously reported absence of the expression of CK5/6 in MCF-7 cells [41], our result suggests that these genes are not significantly expressed in either MCF-7-Snail or MCF-7-Control cells. Although the EGFR gene appears to be expressed over the calculated threshold, and up-regulated in MCF-7-Snail cells (Additional file 2: Figure S5b, Additional files 3 and 4), its signal intensity is low (Additional file 2: Figure $\mathrm{S} 1 \mathrm{~B})$. Moreover, the ITGB4 gene previously associated with the basal-like subtype [42] is down regulated in MCF-7-Snail cells (Additional files 3 and 4).

Overall, our gene expression results do not support the basal-like phenotype for MCF-7-Snail cells. In contrast, genes whose down regulation is known to be associated with the claudin-low subtype (CLDN3, CLDN4, CLDN7, CDH1, and ITGB4) [42] are all significantly down regulated in MCF-7-Snail cells (Fig. 6b, Additional file 2: Figure S1B, Additional file 3 and Additional file 4). Collectively, our findings indicate that ectopic expression of Snail has induced the transformation of $M C F-7$ cells from the luminal A-like cells to the claudin-low triplenegative breast cancer subtype.

\section{Levels of reactive oxygen species (ROS) are significantly elevated in MCF-7-Snail cells}

Reactive oxygen species (ROS) are known to induce a variety of cellular responses contributing to the development and progression of breast and other types of cancer [43]. Since our systems analyses indicated that ROS-associated cellular process networks are enriched by genes differentially expressed between MCF-7-Snail and MCF-7-Control cells (Table 2), we explored the possibility that the ectopic expression of Snail in MCF-7 cells might be associated with changes in levels of ROS contributing to the process of EMT and other Snailmediated phenotypic changes in MCF-7-Snail cells. The results, presented in Fig. 7, are consistent with this hypothesis and demonstrate significantly higher levels of ROS in mesenchymal-like $M C F-7-S n a i l$ cells relative to the MCF-7-Controls. These results are also consistent with recently reported findings in mesenchymal-like prostate cancer cells [44].

\section{Elevated levels of ROS in MCF-7-Snail cells are associated with decreased levels of cellular glutathione and NF-KB activity}

Increased intracellular concentrations of ROS in cancer cells have been previously associated with decreased levels of antioxidant enzymes and/or glutathione [45]. We compared intracellular levels of glutathione in MCF-7Snail and MCF-7-Control cells using a luminescence-based assay. The results presented in Fig. 8a demonstrate lower levels of both reduced (GSH) and total (GSH+GSSG) glutathione levels in MCF-7-Snail cells relative to MCF-7-Controls.

ROS have been shown to induce EMT in mouse mammary epithelial cells via NF- $\mathrm{B}$-mediated activation of Snail [46]. In addition, NF-kB was reported to play an essential role in the induction and maintenance of EMT in breast cancer [47]. Given the previously observed associations between the ROS and NF- $\mathrm{B}$ activity in breast and other cancer types [48], we compared the status of NF-kB activity in MCF-7-Snail and MCF-7- 


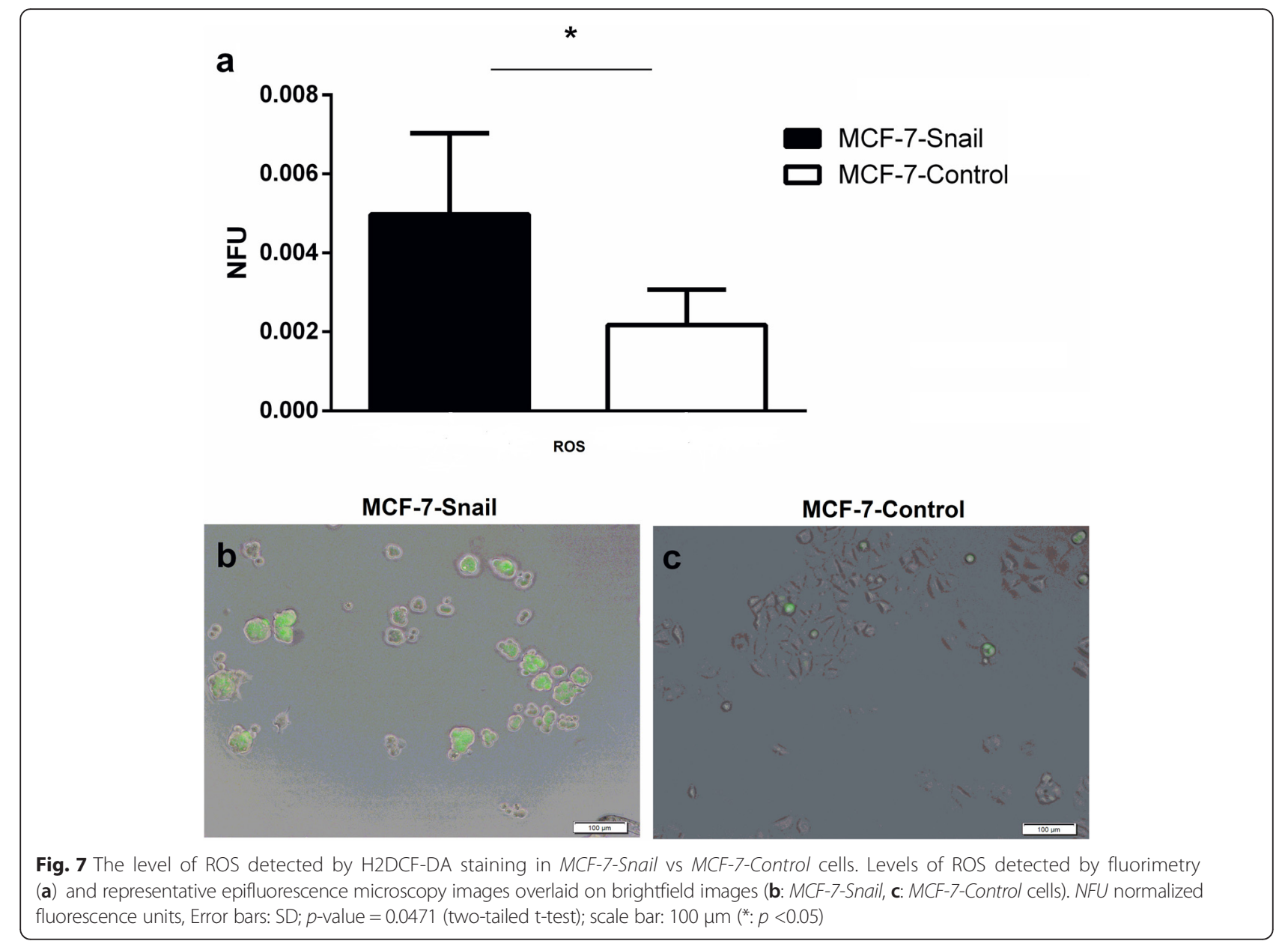

Control cells. Our microarray data indicate down regulation of the NF-KB1 gene in MCF-7-Snail cells (Additional files 3 and 4). In addition, we found that the NF-kB transcription network is enriched by genes differentially expressed between MCF-7-Snail and MCF-7-Control cells (Additional file 6). NF- $\mathrm{kB}$ transcript levels do not necessarily correlate with NF- $\mathrm{KB}$ activity since the protein is activated by proteasome degradation of $I \kappa \mathrm{B}$, and the subsequent translocation of NF- $\mathrm{kB}$ dimers from the cytoplasm to the nucleus [49]. Thus, measurement of NF-kB protein levels in cell nuclei is necessary for biologically accurate estimates of NF- $\mathrm{kB}$ activity. We determined the level of NF- $\mathrm{BB}$ (p50/ p65- the most common member of NF- $\mathrm{kB} /$ Rel family) by its quantification in nuclear protein extracts using an ELISA-based method. The results, presented in Fig. 8b, demonstrate a significant decrease in nuclear protein levels of NF-kB in MCF-7-Snail cells relative to controls indicating decreased nuclear translocation and activation.

The consequence of ectopic expression of Snail on drug sensitivity is variable

Since EMT has been reported by several groups to enhance the resistance of cancer cells to anticancer drugs (reviewed in [9]), we evaluated the relative sensitivity of MCF-7-Snail and MCF-7-Control cells to a variety of cancer drugs previously and/or currently employed in breast cancer treatment (vincristine, doxorubicin [50], mitomycin C, methotrexate [51], gemcitabine, cisplatin [52] and 5-fluorouracil [53]). The sensitivity assay was designed to compare numbers of viable cells in drug-treated cell cultures relative to untreated controls independent of the specific mechanisms of cell cytotoxicity. $\mathrm{GI}_{50}$ values for each drug and cell type (Fig. 9) were determined from dose response curves (Additional file 2: Figure S7).

The results indicate that mesenchymal-like MCF-7Snail cells are significantly more sensitive to doxorubicin, methotrexate, cisplatin, and 5-fluorouracil relative to epithelial-like MCF-7-Control cells. Conversely, MCF-7-Snail cells display significantly reduced sensitivity to gemcitabine and mitomycin $\mathrm{C}$. While the difference in $\mathrm{GI}_{50}$ values between the two cell types is statistically significant for MMC, the fold change $(\sim 1.6 \times)$ is relatively low and, thus, of questionable biological significance. MCF-7-Snail and MCF-7-Control cells did not display significant differences in sensitivity to vincristine. 

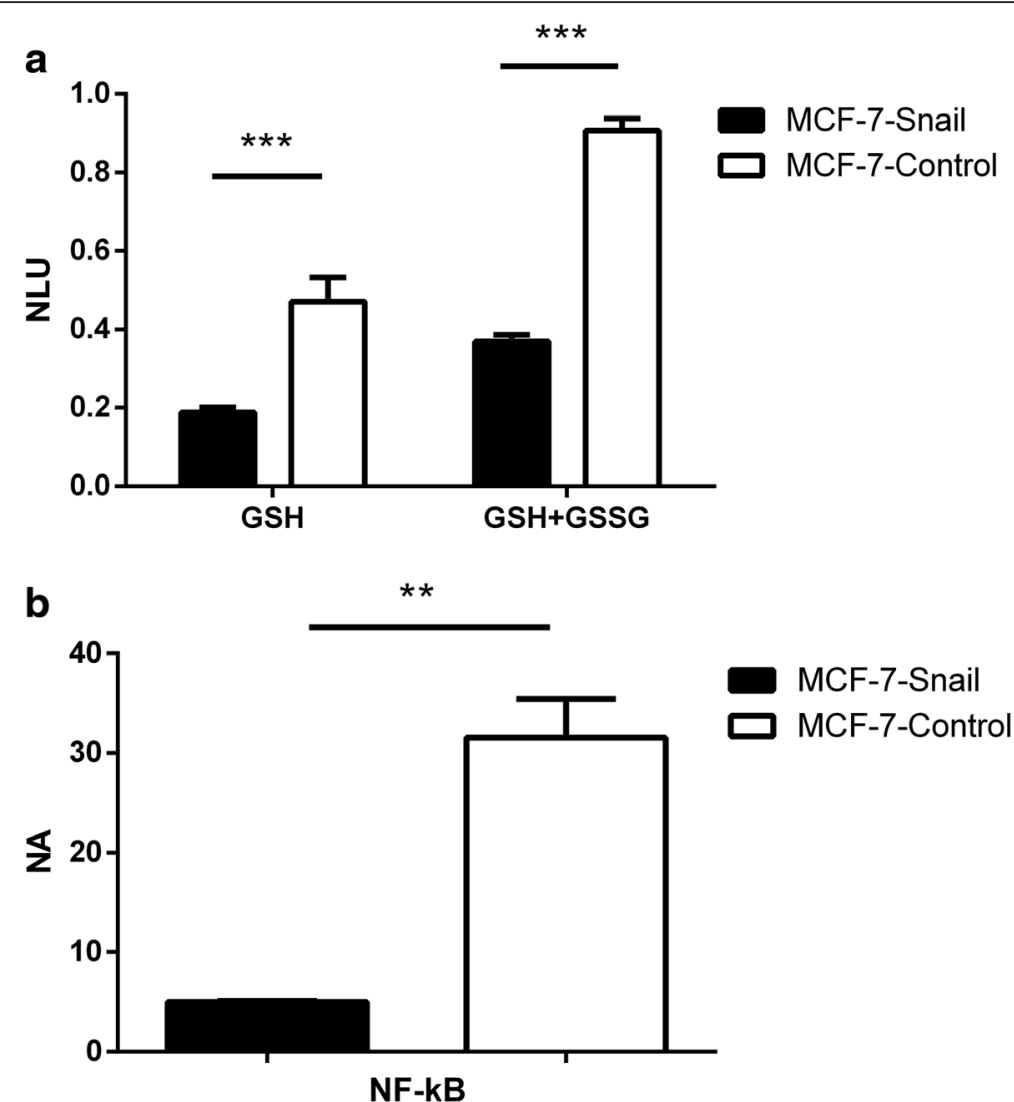

MCF-7-Snail

$\square$ MCF-7-Control

NF-kB

Fig. 8 Levels of GSH, GSH+GSSG and nuclear NF-kB. a Levels of free (GSH) and total (GSH+GSSG) glutathione in MCF-7-Snail and MCF-7-Control cells determined by luminescent assay; NLU normalized luminescence units; $p$-values (multiple t-test with Holm-Šidák correction): GSH $=9.98 \times 10^{-5}$; $\mathrm{GSH}+\mathrm{GSSG}=8.46 \times 10^{-8}$. $\mathbf{b}$ Levels of nuclear NF-KB in MCF-7-Snail and MCF-7-Control cells expressed as determined by ELISA in nuclear protein lysates; NA normalized absorbance; Error bars: SD; $p=0.0071$ (Welch's corrected t-test; **: $p<0.01 ;{ }^{* * *}: p<0.001$ )

Differences in sensitivity of MCF-7-Snail and MCF-7Control cells to some anticancer drugs tested in this work can be interpreted in the context of changes in the expression of genes known to contribute to resistance against specific anticancer drugs (Fig. 10). For example, increased sensitivity of MCF-7-Snail cells to cisplatin can be attributed to the combined effect of (i) down regulation of cisplatin-sequestering metallothioneins MT1E, MT1F and MT1G [54], (ii) down regulation of the $\mathrm{ABCC} 3$ transporter [55], down regulation of the nucleotide excision repair enzyme ERCC1 [56], as well as (iii) down regulation of the anti-apoptotic protein XIAP [57], and (iv) decreased concentration of GSH (Fig. 8a). In fact, the lower concentration of GSH in MCF-7-Snail cells likely suppressed the effect of up regulation of GSTP1 in MCF-7-Snail cells that would otherwise contribute to the resistance against cisplatin [58]. Likewise, increased sensitivity of MCF-7-Snail cells to doxorubicin could be attributed to the down regulation of HSPB1 [59] and metallothioneins [60], while increased sensitivity to 5 -FU can be attributed to the down regulation of DPYD in MCF-7-Snail cells [61]. On the other hand, lower sensitivity of MCF-7-Snail cells to gemcitabine can be attributed to the up regulation of its target, RRM1 [62]. Overall, these results indicate that EMT is not always associated with increased resistance to anticancer drugs.

\section{MCF 7-Snail cells display increased radiosensitivity relative to MCF-7-Controls}

Radiotherapy is an important treatment modality for breast cancer [63]. The efficacy of radiotherapy, however, can be decreased by intrinsic or acquired resistance [64] possibly associated with EMT $[8,65]$. To explore this relationship in our experimental system, we exposed MCF-7-Snail and MCF-7-Control cells to a single dose of X-ray radiation at 2-8 Gy and cells were allowed to replicate for $72 \mathrm{~h}$ at which point the number of metabolically active viable cells was determined. The results demonstrate a significantly lower proportion of viable MCF-7-Snail cells at 72-hours post-irradiation (Fig. 11) indicating higher radiation sensitivity of the mesenchymallike MCF-7-Snail cells relative to epithelial-like MCF-7Control cells. Consistent with the response to radiation 


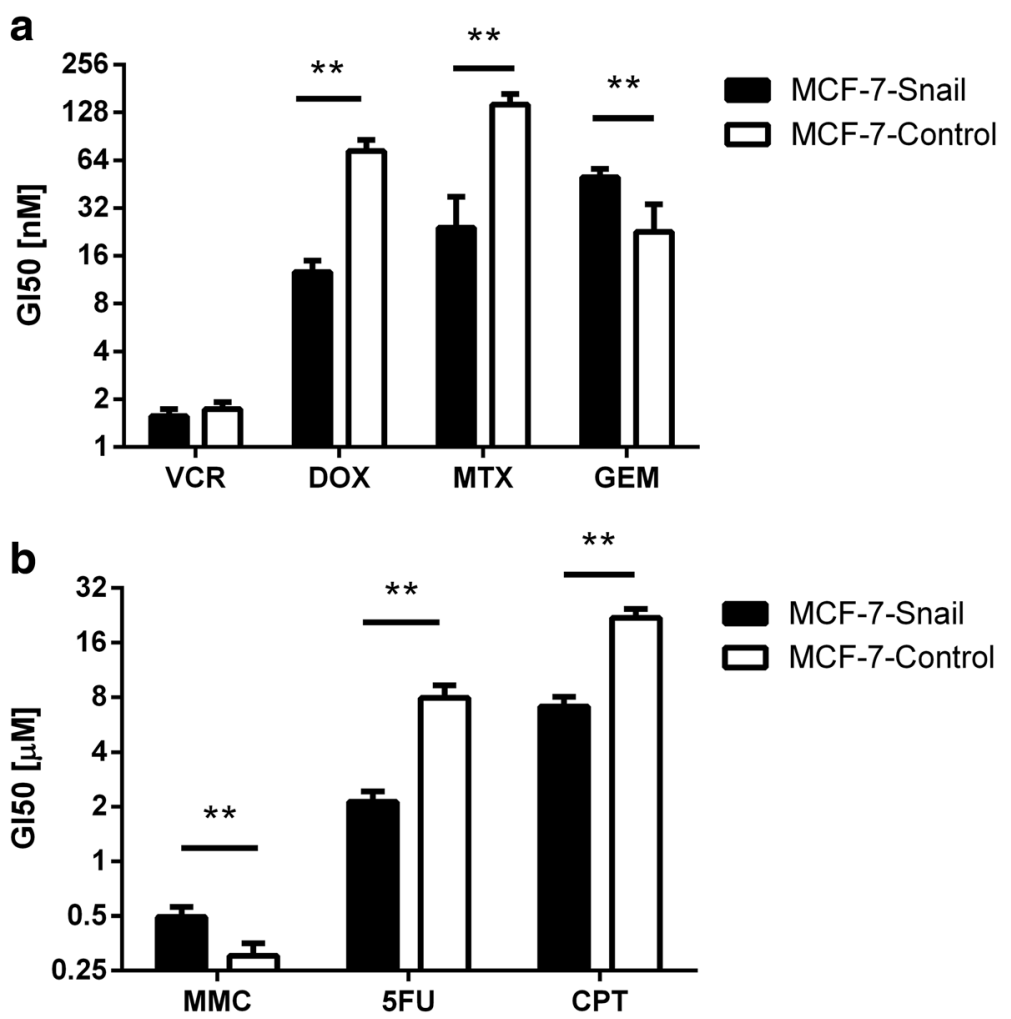

Fig. 9 Drug sensitivity for MCF-7-Snail and MCF-7-Control cells determined by Tox-8 assay and expressed as GI50 values. a vincristine (VCR), doxorubicin (DOX), methotrexate (MTX), gemcitabine (GEM); b mitomycin C (MMC), 5-fluorouracil (5FU), cisplatin (CPT). Error bars: SD; $N=4$ replicates. Statistical significance of differences between mean GI50 values determined by t-test corrected by Holm-Šidák method $(* *: p<0.01)$

treatment, we also observed prominent multinucleated cells in cultures of irradiated MCF-7-Snail cells (Fig. 11) indicative of radiation-induced deregulation of mitosis and deficient separation of nuclei during cytokinesis [66, 67].

Since radiosensitivity has previously been shown to be dependent on the phase of the cell cycle [68], we examined the distribution of MCF7-Snail and MCF7-Control cells in specific phases of the cell cycle before irradiation. Cultures of MCF-7-Snail and MCF-7-Control cells plated at densities identical to those used in the radiation sensitivity experiments displayed a significantly higher proportion of MCF-7-Snail cells in the G2/M phase relative to $M C F-7-C o n t r o l$ cells (Holm-Šidák corrected t-test $p=0.0059$; CI95 $=2.483-14.29 \%)$. Differences in the proportion of the two cell types in G0/ G1 and S phases of the cell cycle were not significant (Fig. 12 and Additional file 2: Figure S8). Since cells are known to display their greatest sensitivity to irradiation during mitosis and G2 phases of the cell cycle [69], the higher proportion of MCF-7-Snail cells in the G2/M phase of the cell cycle may contribute to their higher radiosensitivity relative to $M C F-7-C o n t r o l$ cells.

However, different slopes of semi-log radiosensitivity plots at a medium-high dose range (Additional file 2: Figure S9) suggest that the observed difference in the radiosensitivity between MCF-7-Snail and MCF-7-Control cells cannot be attributed only to the cell cycle differences. In an initial effort to identify molecular differences potentially responsible for the observed differences in radiation sensitivity of these two cell types, we focused on genes previously associated with radiation resistance in breast and other cancers and found that many of them were significantly down regulated in MCF-7-Snail cells (Additional file 4), e.g. IGF1R (insulin-like growth factor one receptor) [70], REG4 (Regenerating isletderived protein four) [71], RALBP1 (RalA-binding protein one) [72] and ERCC1 (excision repair crosscomplementation group one) [73]) suggesting their potential involvement in the increased sensitivity of MCF-7-Snail cells to radiation treatment.

\section{Discussion}

An abundance of prior evience indicates that breast cancer progression and the development of $\mathrm{MBC}$ is intimately associated with EMT [74-76]. In addition, EMT has also been associated with the resistance of breast and other cancers to a variety of anticancer drugs [9] and ionizing radiation $[8,65]$. While dysregulation of the transcription factor Snail has been previously associated with EMT in breast and other cancers [10, 12], its 


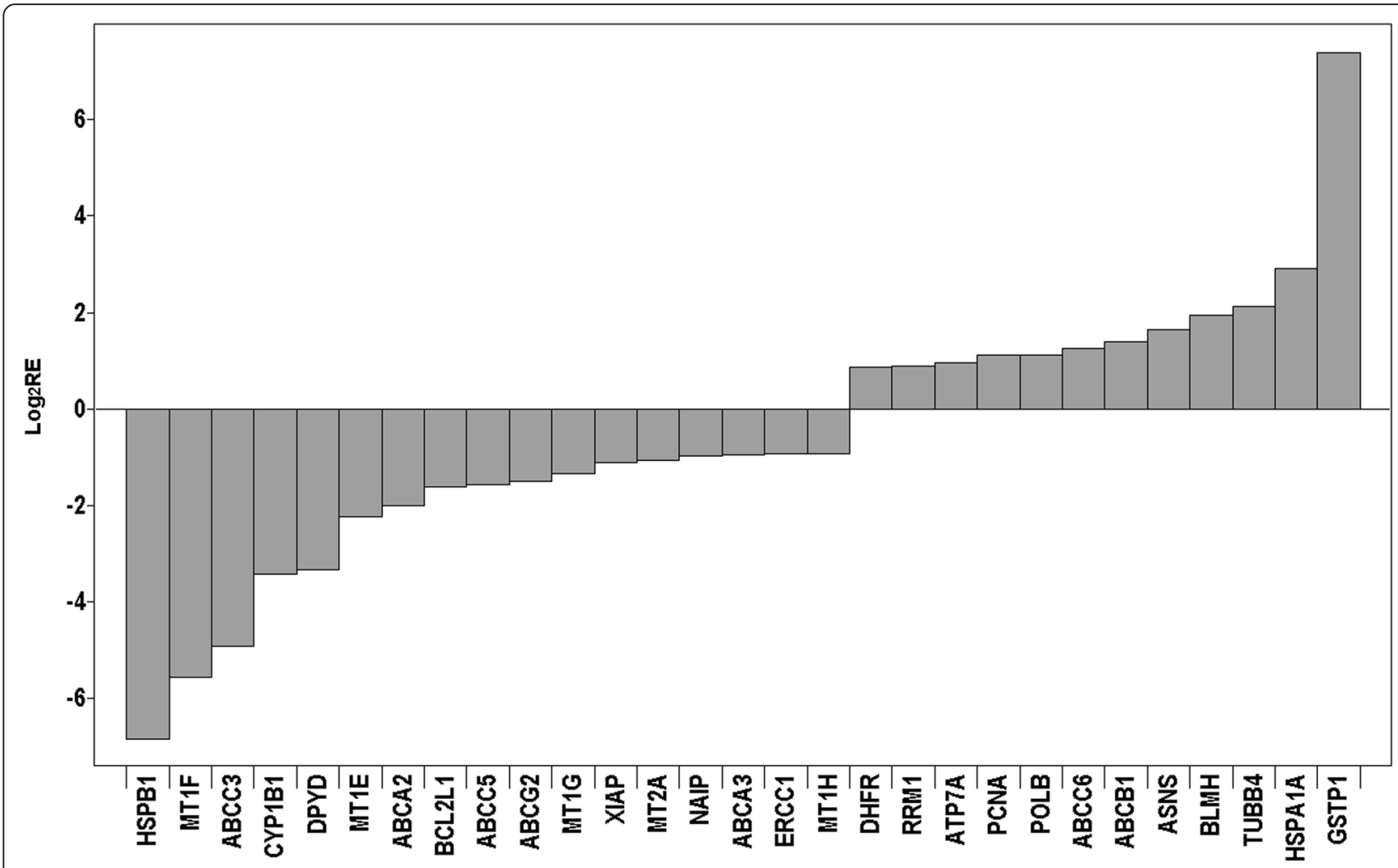

Fig. 10 Relative expression of a subset of 53 drug resistance-related genes that displayed significantly different expression in MCF-7-Snail relative to MCF-7-Control cells. Relative expression from microarray data is presented in log2 scale

effect on system-wide molecular changes and consequent changes in response to radiation and drug therapies is incompletely understood. In an effort to better understand the role of Snail in breast cancer development, we examined an isogenic pair of breast cancer cell lines MCF-7-Snail and MCF-7-Control. MCF-7-Snail cell line has been previously engineered to ectopically express Snail [14]. Detailed anayses of MCF-7-Snail cells provides a unique opportunity to evaluate biologically and clinically significant consequences of Snail-induced EMT in breast cancer.

Previous studies have demonstrated that MCF-7-Snail cells display reduced expression of the epithelial marker E-cadherin (CDH1), increased expression of the mesenchymal markers VIM and FN1 and enhanced migratory capabilities relative to controls [14]. Consistent with these earlier findings, our microarray analyses of $M C F$ 7-Snail cells demonstrate concerted changes in the expression of a number of genes and pathways previously implicated in EMT [25]. Among the genes significantly up regulated/activated in response to ectopic Snail expression are several key transcription factors known to be critical to EMT development (reviewed in [77]). For example, the initial stages of EMT are believed to require Snail-induced repression of E-cadherin, while subsequent maintenance may require cooperation of other key transcription factors, including Slug, E47, Zeb2 and Twist [77]. Consistent with these expectations, we observed significant down regulation of E-cadherin and up regulation of Slug, E47, Zeb2, and Twist 1 in MCF-7-Snail relative to MCF-7-Control cells.

Snail and Slug are believed to work cooperatively in EMT [77-79]. Our results suggest that the mechanism for Snail-mediated up regulation of Slug is through the down regulation of estrogen receptor 1 (ESR1). Snail is a known transcriptional repressor of ESR1 [80] that, in turn, is a documented transcriptional repressor of Slug [81]. Consistent with this interactive model, we observed a significant up regulation of Slug and concurrent down regulation of ESR1 in MCF-7-Snail cells relative to controls. Interestingly, this down regulation of ESR1 was found be correlated with other molecular changes indicative of Snail-induced transformation of MCF-7 cells from the luminal A to the clinically more aggressive triple-negative, claudin-low sub-type. This finding is consistent with the potential of Snail-targeted therapy for the treatment of metastatic breast cancer [82].

Interactions between Snail and Slug may also contribute to our observed down regulation in the expression of the miR-200 family of microRNAs in MCF-7-Snail cells. In agreement with prior studies implicating members of the miR-200 family of microRNAs with EMT/ 

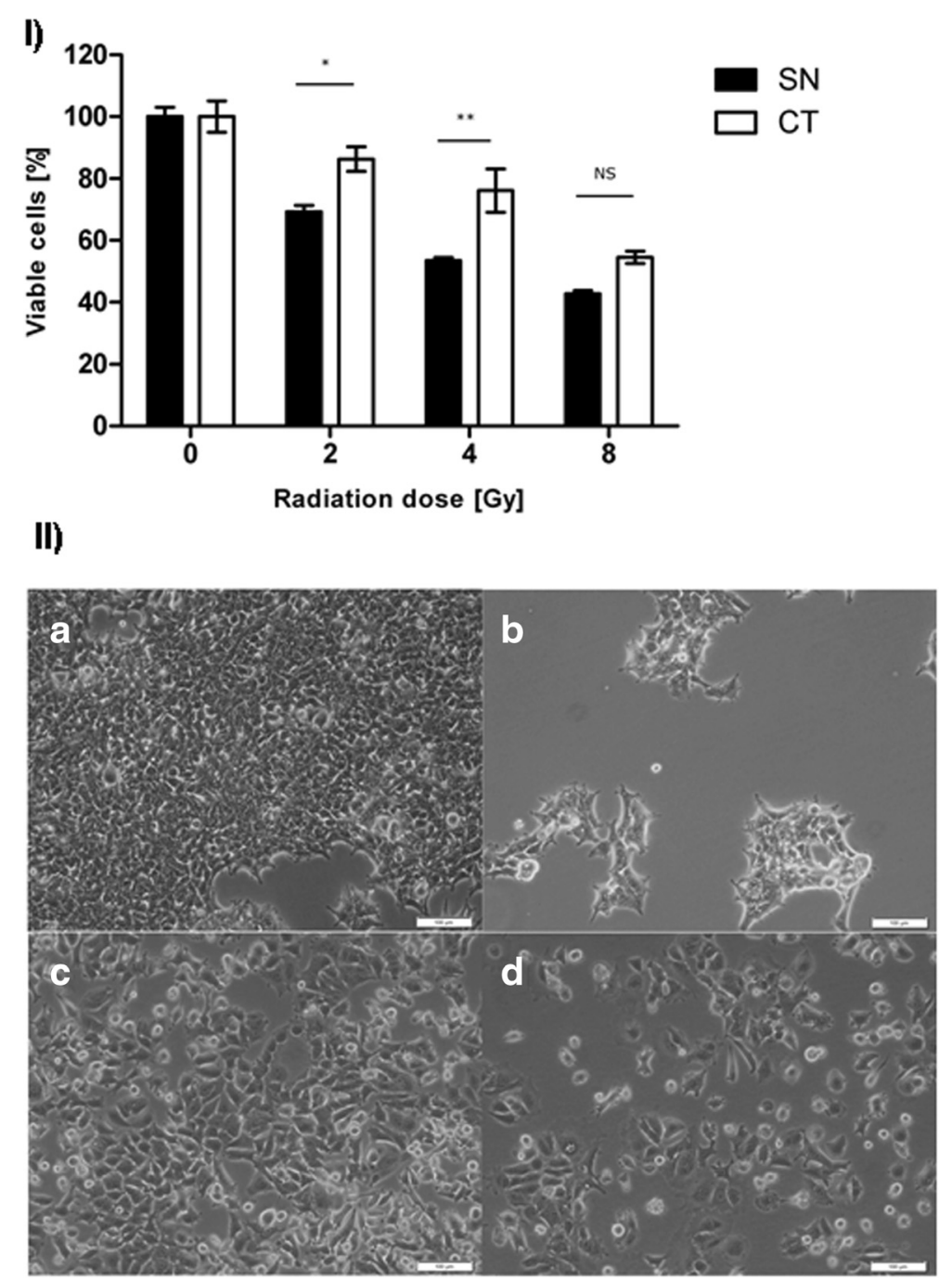

Fig. 11 Radiation sensitivity for MCF-7-Snail and MCF-7-Control cells. I Radiation sensitivity determined from the number of viable cells $72 \mathrm{~h}$ post-irradiation by specified doses of X-ray. Viable cells [\%] corresponds to the number of viable cells determined by Tox-8 assay in treatment relative to non-irradiated control cultures ( $N=2$ replicates; $*$ : $p<0.05 ; * *: p<0.01)$; error bars $=$ SD. II Micrographs of MCF-7-Snail $(a, b)$ and MCF-7-Control cells $(c, d) 72 \mathrm{~h}$ post-irradiation with 0 Gy $(a, c)$ or 4 Gy $(b, d)$. Scale bar: $100 \mu \mathrm{m}$. SN = MCF-7-Snail cells; CT = MCF-7-Control cells

MET (mesenchymal-to-epithelial transition) [28, 32, 33], we observed a significant down regulation of members of the miR-200 family in MCF-7-Snail cells. Our gene expression analyses suggest several possible mechanisms by which ectopic expression of Snail in MCF-7 cells may be contributing to repression of miR-200 family of miRNAs.

Although Snail has been previously implicated as an activator of Zeb1 [83] and Zeb2 [84], both of which are well-established transcriptional repressors of miR-200 family members [85], Snail-activation of Zeb1/2 is believed not to be direct $[83,86]$. In contrast, Slug is known to be a direct transcriptional activator of Zeb1 [86] and can itself directly repress transcription of miR-200 family members [87]. Thus,
Snail-induced activation of Slug in MCF-7-Snail cells may contribute to the down regulation of miR-200 family microRNAs.

Our results also demonstrate a significant down regulation of the transcription factor Krüppel-like factor 5 (KLF5) in MCF-7-Snail cells (Additional files 3 and 4). KLF5 is a known transcriptional activator of miR-200 family members, as well as several other microRNAs previously implicated in EMT (e.g., miR-205 and Let-7a/ $7 \mathrm{~b} / 7 \mathrm{c} / 7 \mathrm{~d} / 7 \mathrm{e} / 7 \mathrm{~g}$ ) [88]. It has been previously suggested that KLF5-Smads-p300 complexes activate while ZEB1/ 2-Smads-p300 complexes repress the transcription of miR-200, and that KLF5 and ZEB1/2 may physically interact or compete to execute opposing functions in miR-200 regulation [88]. 


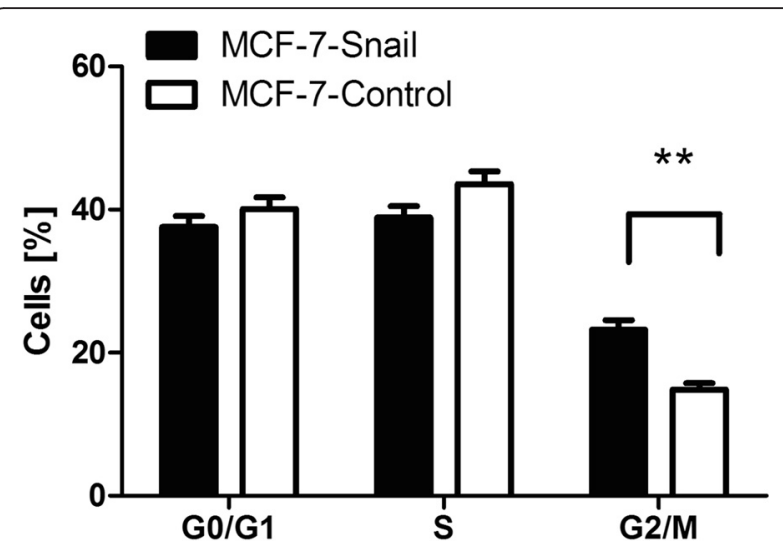

Fig. 12 Cell cycle distribution of MCF-7-Snail and MCF-7-Control cells at the time of $X$-ray irradiation. (means $\pm S E M ; N=3$ replicates; ${ }^{* *}: p<0.01$ )

A third possible mechanism of miR-200 family down regulation suggested by our results involves the nuclear receptor PELP1 and the histone deacetylase HDAC2. Both of these genes were found to be significantly up regulated in MCF-7-Snail cells (Additional files 3 and 4). It has recently been shown that PELP1, in cooperation with histone deacetylase $\mathrm{HDAC2}$, can transcriptionally repress mir-200 family microRNAs [89]. Interestingly, we also found that MYC, a known transcriptional activator of PELP1 [90], is functionally activated in MCF7-Snail cells. None of the above possible modes of miR-200 family repression are mutually exclusive and suggest a redundant and highly interactive nature of Snail regulatory controls.

Previous studies have implicated Snail-induced activation of TGF- $\beta$ with EMT in breast cancer cells $[91,92]$. While our pathway enrichment analysis identified "TGFbeta-dependent induction of EMT via SMADs" as a significantly enriched pathway (Table 1), this does not necessarily imply TGF- $\beta$ activation. In fact, our gene expression analysis indicates down-regulation of TGFB13, SMAD2 and SMAD3 genes in MCF-7-Snail cells (Additional files 3 and 4) which argues against activation of TGF- $\beta$ mediated signaling via receptor-regulated Smads [93]. In addition, we failed to observe up regulation of known downstreatm targets of TGF- $\beta$ (e.g., CTGF, ligand TGFB2 and receptor TGFBR2) in MCF-7Snail cells, again suggesting the absence of TGF- $\beta$-signaling. Consistent with these findings, previous studies of claudin-low breast cancer subtypes indicate that Snail-induced EMT need not be dependent on TGF$\beta$-mediated autocrine signaling [92].

Several previous studies have noted an interactive relationship between changes in the expression of key regulatory genes and intracellular levels of ROS in EMT $[44,46,94]$. This regulatory relationship coupled with their association with oxidative damage and chronic inflammation has identified ROS as a major contributing factor in the progression of breast and other cancers [43, 94]. Our finding that ROS levels are significantly elevated in MCF-7-Snail cells is consistent with these and other results indicating that elevated levels of ROS contribute to EMT and the maintenance of the mesenchymal phenotype in metastatic cancer cells.

Several studies have previously correlated increasing levels of ROS with activation of the transcription factor NF- $k B$, possibly as part of the stress response pathway [48]. For example, ROS were shown to activate NF- $\kappa B$ that subsequently induced the expression of Snail in MMP3-mediated EMT of mammary epithelial cells [46]. In contrast to expectations, we observed a significant decrease in the expression of NF-KB1 in MCF-7-Snail cells relative to controls. We also observed a decrease in nuclear protein levels of $N F-\kappa B$ in MCF-7-Snail cells indicating reduced NF- $\mathrm{KB}$ activation in these cells. Collectively, our results indicate that Snail-induced increases in intracellular levels of ROS are not coupled with NF- $\mathrm{kB}$ activation in MCF-7-Snail cells. The reduced activation of NF- $\mathrm{kB}$ in MCF-7-Snail cells may be associated with glutathione depletion, consistent with a previously report that demonstrated IкB kinase-dependent and independent down-regulation of NF- $\mathrm{KB}$ activity upon glutathione depletion [95].

In addition to a systems analysis of the molecular consequences of Snail-induced EMT in MCF-7 cells, we were also interested in documenting the effect of these molecular changes on drug and radiation sensitivity. A number of prior studies have suggested that EMT is associated with increased resistance of cancer cells to anticancer drugs (reviewed in [9]). However, our findings suggest that this generalization may not be universally correct. While we found that MCF-7-Snail cells are significantly more resistant to gemcitabine and mitomycin $C(M M C)$, they were significantly more sensitive to doxorubicin, methotrexate, cisplatin, and 5-fluorouracil. Similar inconsistencies between EMT and drug sensitivities have been previously reported [96-98]. For example, in a survey of the sensitivity of 54 adherent human cancer cell lines from the NCI-60 cell panel, statistically significant positive correlations between expression levels of the epithelial biomarker E-cadherin and drug sensitivity was found for only ten out of 118 drugs [96]. In another study, non-small cell lung cancer (NSCLC) cells designated as mesenchymal-like based on their molecular profile, were found to be more resistant than epitheliallike NSCLC cells to erlotinib and the PI3K/AKT/mTOR inhibitors GDC0941 and 8-aminoadenosine, but more sensitive to pemetrexed, paclitaxel and docetaxel [97]. Similarly, two mesenchymal-like pancreatic cancer cell lines were found to display greater sensitivity to paclitaxel than epithelial-like pancreatic cancer cell lines [98]. 
Collectively, these findings indicate that epithelialmesenchymal cellular phenotypes, per se, are not reliable predictors of relative drug sensitivity. While such inconsistencies may simply be attributable to other differences between cell lines that are not consistently associated with epithelial or mesenchymal phenotype, it may also be a reflection of a continuum of potential EMT-mediated effects on cellular phenotypes [99].

Another reflection of the inconsistency of EMTmediated effects on cellular phenotypes is our finding that mesenchymal-like MCF-7-Snail cells are more sensitive to radiation treatment than their parental epithelial-like cells. In contrast to our results, a number of previous studies have associated EMT and the mesenchymal cell phenotype with increased radioresistance $[8,65]$. For example, epithelial ovarian cancer cells, in which the ectopic expression of Snail or Slug resulted in the acquisition of stem cell-like properties, were found to be associated with radioresistance [65]. Likewise, mesenchymal-like breast cancer cells that displayed higher resistance to radiation than their parental epithelial-like cells, were also found to exhibit a stem cell-like phenotype including a CD $44^{+} / \mathrm{CD} 24^{-/ \text {low }}$ molecular signature [100]. One possible explanation of the apparent discrepancy between our results and the accumulated evidence that mesenchymal-like cancer cells are generally associated with radiation resistance (reviewed in [101]) is that it is the stem cell-like properties of these cells and not EMT per se that is responsible for their radiation resistance. While stem cells typically display a mesenchymal-like phenotype, not all EMT-induced mesenchymal-like cells may display features characteristic of stem cells. For example, it has been previously shown that cancer stem cells typically contain lower levels of ROS than their more differentiated progeny and that this difference is critical for the maintenance of stem cell phenotype [102]. In contrast, we found that MCF-7-Snail cells contain higher levels of ROS than MCF-7-Control cells. In addition, MCF-7-Snail cells display down regulation of Sox 2 and Nanog (Additional files 3 and 4) that have been previously shown to contribute to the maintenance of pluripotency and the self-renewal properties of human embryonic stem cells [103]. In addition, we found that other stem cell biomarkers are also down regulated or unchanged in expression in MCF-7-Snail cells relative to controls (e.g., UTF1 [104], FBXO15 [105], ALDH1A3 [106], CD44, CD133 and ITGB1 [107]). Furthermore, previous studies have also reported down-regulation of several genes associated with stem cell phenotype early (ABCG2 [108], CD44, ALDH1A3) or late (SOX9 [109]) after induction of Snail expression in immortalized human mammary epithelial
MCF10A cells [15]. Collectively, these findings indicate that MCF-7-Snail cells are not stem cell-like cells and that EMT per se does not necessarily lead to the acquisition of resistance to radiation and anticancer drugs.

\section{Conclusions}

Constitutive ectopic expression of Snail in the epitheliallike, luminal A-type, breast cancer cell line $M C F-7$ results in significant changes in the expression $>7600$ genes including master gene and miRNA regulators of EMT. Ectopic expression of Snail induced MCF-7 cells to undergo EMT and to acquire features characteristic of triple-negative, claudin-low breast cancer cells but not of breast cancer stem-like cells. Snail-induced EMT of MCF-7 cells resulted in increased sensitivity to radiation treatment but increased, decreased or no change in sensitivity to a variety of anticancer drugs indicating that EMT is not necessarily predictive of decreased responsiveness to therapeutic treatments. These results underscore the complexity and cell-context dependent nature of EMT-mediated changes in breast cancer cells.

\section{Availability of supporting data}

A detailed description of the microarray experiment and the resulting data are available in the Gene Expression Omnibus repository (GEO, http://www.ncbi.nlm.nih.gov/ geo/) under the accession number GSE58252.

\section{Additional files}

Additional file 1: List of 71 genes relevant to EMT and 53 genes relevant to anticancer drug resistance assembled by manual curation from appended references. (XLSX $54 \mathrm{~kb}$ )

Additional file 2: Supplemental Figures S1-S9, supplemental tables S1 and S2 and supplemental methods S1-S3. (PDF $528 \mathrm{~kb}$ )

Additional file 3: List of 12,104 probe sets corresponding to differentially expressed transcripts between MCF-7-Snail and MCF-7-Control cells identified by Significance Analysis of Microarray (FDR $=2.12 \%$ and $|F C| \geq 1.5$ ). (XLSX $2199 \mathrm{~kb}$ )

Additional file 4: List of 7602 unique annotated genes differentially expressed between MCF-7-Snail and MCF-7-Control cells. (XLSX $178 \mathrm{~kb}$ )

Additional file 5: List of 164 network objects from the MetaCore human protein interactome that are statistically significantly overconnected to the genes differentially expressed between MCF-7-Snail and MCF-7-Control cells. (XLS $71 \mathrm{~kb}$ )

Additional file 6: List of 31 significant networks centered on transcription factors built from genes differentially expressed between MCF-7-Snail and MCF-7-Control cells. (XLS 39 kb)

Additional file 7: List of differentially expressed genes between MCF-7-Snail and MCF-7-Control cells known to MetaCore knowledgebase to be directly transcriptionally regulated by c-Myc. (XLS 610 kb)

Additional file 8: List of differentially expressed genes between MCF-7-Snail and MCF-7-Control cells known to MetaCore knowledgebase to be directly transcriptionally regulated by ESR-1. (XLS 339 kb)

Additional file 9: List of gene sets from C2: Curated Gene Sets and C6: Oncogenic Signatures gene sets (http://www.broadinstitute.org/gsea/ msigdb/collections.jsp) significantly enriched in MCF-7-Snail or MCF-7Control phenotypes. (XLSX $24 \mathrm{~kb}$ ) 


\section{Abbreviations}

CSC: cancer stem-like cells; DOX: doxorubicine; EMT: epithelial-tomesenchymal transition; 5-FU: 5-fluorouracil; GEM: gemcitabine; GSH: glutathione (reduced form); GSSG: glutathione (oxidized disulfide form); H2DCF-DA: 2',7'-dichlorodihydrofluorescein diacetate; MBC: metastatic breast cancer; MMC: mitomycin C; MTX: methotrexate; NSCLC: non-small cell lung cancer; ROS: reactive oxygen species; VCR: vincristine.

\section{Competing interest}

The authors declare that they have no competing interest.

\section{Authors' contributions}

RM and JM conceived the study and wrote the manuscript. RM performed the experiments, analyzed and interpreted the data. LM processed cells for RNA and generated the microarray data files. NJ took part in drug sensitivity tests. All authors read and approved the final manuscript.

\section{Funding}

This work was supported by an endowment from The Deborah Nash Foundation.

\section{Received: 16 April 2015 Accepted: 13 March 2016}

Published online: 18 March 2016

\section{References}

1. Ferlay J, Soerjomataram I, Ervik M, Dikshit R, Eser S, Mathers C, et al. GLOBOCAN 2012 v1.0, Cancer Incidence and Mortality Worldwide: IARC CancerBase No. 11 [Internet]. 2013. http://globocan.iarc.fr. Acessed 07/01/2014

2. Lu J, Steeg PS, Price JE, Krishnamurthy S, Mani SA, Reuben J, et al. Breast cancer metastasis: challenges and opportunities. Cancer Res. 2009;69:4951-3.

3. Kennecke $H$, Yerushalmi R, Woods R, Cheang MCU, Voduc D, Speers $\mathrm{CH}$, et al. Metastatic behavior of breast cancer subtypes. J Clin Oncol. 2010;28:3271-7.

4. Bolender DL, Markwald RR. Epithelial-mesenchymal transformation in chick atrioventricular cushion morphogenesis. Scan Electron Microsc. 1979;3:313-21.

5. Baum B, Settleman J, Quinlan MP. Transitions between epithelial and mesenchymal states in development and disease. Semin Cell Dev Biol. 2008;19:294-308.

6. Yang J, Mani SA, Donaher JL, Ramaswamy S, Itzykson RA, Come C, et al. Twist, a master regulator of morphogenesis, plays an essential role in tumor metastasis. Cell. 2004:117:927-39.

7. Thiery JP, Acloque H, Huang RY, Nieto MA. Epithelial-mesenchymal transitions in development and disease. Cell. 2009;139:871-90.

8. Theys J, Jutten B, Habets R, Paesmans K, Groot AJ, Lambin P, et al. E-Cadherin loss associated with EMT promotes radioresistance in human tumor cells. Radiother Oncol. 2011;99:392-7.

9. Foroni C, Broggini M, Generali D, Damia G. Epithelial-mesenchymal transition and breast cancer: role, molecular mechanisms and clinical impact. Cancer Treat Rev. 2012;38:689-97.

10. Lamouille S, Xu J, Derynck R. Molecular mechanisms of epithelial-mesenchymal transition. Nat Rev Mol Cell Biol. 2014;15:178-96.

11. Nieto MA. The snail superfamily of zinc-finger transcription factors. Nat Rev Mol Cell Biol. 2002;3:155-66.

12. de Herreros AG, Peiro $S$, Nassour M, Savagner P. Snail family regulation and epithelial mesenchymal transitions in breast cancer progression. J Mammary Gland Biol Neoplasia. 2010;15:135-47.

13. Soule HD, Vazquez J, Long A, Albert S, Brennan M. Human cell line from a pleural effusion derived from a breast carcinoma. J Natl Cancer Inst. 1973;51:1409-16

14. Zhou BP, Deng J, Xia W, Xu J, Li YM, Gunduz M, et al. Dual regulation of Snail by GSK-3beta-mediated phosphorylation in control of epithelialmesenchymal transition. Nat Cell Biol. 2004;6:931-40

15. Javaid S, Zhang J, Anderssen E, Black JC, Wittner BS, Tajima K, et al. Dynamic chromatin modification sustains epithelial-mesenchymal transition following inducible expression of Snail-1. Cell Rep. 2013;5:1679-89.

16. Smith BN, Burton LJ, Henderson V, Randle DD, Morton DJ, Smith BA, et al. Snail promotes epithelial mesenchymal transition in breast cancer cells in part via activation of nuclear ERK2. PLoS One. 2014;9:e104987.
17. Tusher VG, Tibshirani R, Chu G. Significance analysis of microarrays applied to the ionizing radiation response. Proc Natl Acad Sci U S A. 2001:98:5116-21.

18. Saviozzi S, lazzetti G, Caserta E, Guffanti A, Calogero RA. Microarray data analysis and mining. Methods Mol Med. 2004:94:67-90.

19. Shi W, Bessarabova M, Dosymbekov D, Dezso Z, Nikolskaya T, Dudoladova $M$, et al. Functional analysis of multiple genomic signatures demonstrates that classification algorithms choose phenotype-related genes. Pharmacogenomics J. 2010;10:310-23.

20. Bessarabova M, Ishkin A, JeBailey L, Nikolskaya T, Nikolsky Y. Knowledge-based analysis of proteomics data. BMC Bioinformatics. 2012;13 Suppl 16:S13.

21. Subramanian A, Tamayo P, Mootha VK, Mukherjee S, Ebert BL, Gillette MA, et al. Gene set enrichment analysis: a knowledge-based approach for interpreting genome-wide expression profiles. Proc Natl Acad Sci U S A. 2005;102:15545-50.

22. Pfaffl MW, Horgan GW, Dempfle L. Relative expression software tool (REST (c)) for group-wise comparison and statistical analysis of relative expression results in real-time PCR. Nucleic Acids Res. 2002;30(9):e36.

23. Mezencev R, Updegrove T, Kutschy P, Repovska M, McDonald JF. Camalexin induces apoptosis in T-leukemia Jurkat cells by increased concentration of reactive oxygen species and activation of caspase- 8 and caspase-9. J Nat Med. 2011;65:488-99.

24. Lebel CP, Ischiropoulos H, Bondy SC. Evaluation of the probe $2^{\prime}, 7^{\prime}$-dichlorofluorescin as an indicator of reactive oxygen species formation and oxidative stress. Chem Res Toxicol. 1992;5:227-31.

25. Zheng $\mathrm{H}$, Kang Y. Multilayer control of the EMT master regulators. Oncogene. 2014;33:1755-63.

26. Medici D, Hay ED, Olsen BR. Snail and Slug promote epithelial-mesenchymal transition through beta-catenin-T-cell factor-4-dependent expression of transforming growth factor-beta3. Mol Biol Cell. 2008;19:4875-87.

27. McGrail DJ, Mezencev R, Kieu QM, McDonald JF, Dawson MR. SNAIL-induced epithelial-to-mesenchymal transition produces concerted biophysical changes from altered cytoskeletal gene expression. FASEB J. 2015;29:1280-9

28. Zhang J, Ma L. MicroRNA control of epithelial-mesenchymal transition and metastasis. Cancer Metastasis Rev. 2012;31:653-62.

29. Korpal M, Lee ES, Hu G, Kang Y. The miR-200 family inhibits epithelial-mesenchymal transition and cancer cell migration by direct targeting of E-cadherin transcriptional repressors ZEB1 and ZEB2. J Biol Chem. 2008;283:14910-4.

30. Liu YN, Yin JJ, Abou-Kheir W, Hynes PG, Casey OM, Fang L, et al. MiR-1 and miR-200 inhibit EMT via Slug-dependent and tumorigenesis via Slug-independent mechanisms. Oncogene. 2013;32:296-306.

31. Chen J, Wang L, Matyunina LV, Hill CG, McDonald JF. Overexpression of miR-429 induces mesenchymal-to-epithelial transition (MET) in metastatic ovarian cancer cells. Gynecol Oncol. 2011:121:200-5.

32. Wang L, Mezencev R, Svajdler M, Benigno BB, McDonald JF. Ectopic overexpression of miR-429 induces mesenchymal-to-epithelial transition (MET) and increased drug sensitivity in metastasizing ovarian cancer cells. Gynecol Oncol. 2014:134:96-103.

33. Park SM, Gaur AB, Lengyel E, Peter ME. The miR-200 family determines the epithelial phenotype of cancer cells by targeting the E-cadherin repressors ZEB1 and ZEB2. Genes Dev. 2008;22:894-907.

34. Gill JG, Langer EM, Lindsley RC, Cai M, Murphy TL, Kyba M, et al. Snail and the microRNA-200 family act in opposition to regulate epithelial-to-mesenchymal transition and germ layer fate restriction in differentiating ESCs. Stem Cells. 2011;29:764-76.

35. Ling $G Q$, Chen DB, Wang BQ, Zhang LS. Expression of the pluripotency markers Oct3/4, Nanog and Sox2 in human breast cancer cell lines. Oncol Lett. 2012:4:1264-8.

36. Takahashi K, Yamanaka S. Induction of pluripotent stem cells from mouse embryonic and adult fibroblast cultures by defined factors. Cell. 2006;126:663-76.

37. Subik K, Lee JF, Baxter L, Strzepek T, Costello D, Crowley P, et al. The expression patterns of ER, PR, HER2, CK5/6, EGFR, Ki-67 and AR by immunohistochemical analysis in breast cancer cell lines. Breast Cancer (Auckl). 2010:4:35-41.

38. Holliday DL, Speirs V. Choosing the right cell line for breast cancer research. Breast Cancer Res. 2011:13:215.

39. Nielsen TO, Hsu FD, Jensen K, Cheang M, Karaca G, Hu Z, et al. Immunohistochemical and clinical characterization of the basal-like subtype of invasive breast carcinoma. Clin Cancer Res. 2004;10:5367-74. 
40. Herschkowitz JI, Simin K, Weigman VJ, Mikaelian I, Usary J, Hu Z, et al. Identification of conserved gene expression features between murine mammary carcinoma models and human breast tumors. Genome Biol. 2007:8:R76.

41. Trask DK, Band V, Zajchowski DA, Yaswen P, Suh T, Sager R. Keratins as markers that distinguish normal and tumor-derived mammary epithelial cells. Proc Natl Acad Sci U S A. 1990;87:2319-23.

42. Perou CM, Sorlie T, Eisen MB, van de Rijn M, Jeffrey SS, Rees CA, et al. Molecular portraits of human breast tumours. Nature. 2000;406:747-52.

43. Waris $\mathrm{G}$, Ahsan $\mathrm{H}$. Reactive oxygen species: role in the development of cancer and various chronic conditions. J Carcinog. 2006;5:14.

44. Barnett P, Arnold RS, Mezencev R, Chung LW, Zayzafoon M, Odero-Marah V. Snail-mediated regulation of reactive oxygen species in ARCaP human prostate cancer cells. Biochem Biophys Res Commun. 2011;404:34-9.

45. Liu RM, Pravia KAG. Oxidative stress and glutathione in TGF-beta-mediated fibrogenesis. Free Radic Biol Med. 2010;48:1-15.

46. Cichon MA, Radisky DC. ROS-induced epithelial-mesenchymal transition in mammary epithelial cells is mediated by NF-kB-dependent activation of Snail. Oncotarget. 2014;5:2827-38.

47. Huber MA, Beug H, Wirth T. Epithelial-mesenchymal transition: NF-kappaB takes center stage. Cell Cycle. 2004;3:1477-80.

48. Morgan MJ, Liu ZG. Crosstalk of reactive oxygen species and NF-kappaB signaling. Cell Res. 2011;21:103-15.

49. Yamamoto Y, Gaynor RB. Therapeutic potential of inhibition of the NF-kappaB pathway in the treatment of inflammation and cancer. J Clin Invest. 2001;107:135-42.

50. Rainey JM, Jones SE, Salmon SE. Combination chemotherapy for advanced breast-cancer utilizing vincristine, adriamycin, and cyclophosphamide (Vac). Cancer. 1979;43:66-71.

51. Powles TJ, Jones AL, Judson IR, Hardy JR, Ashley SE. A randomized trial comparing combination chemotherapy using mitomycin-C, mitoxantrone and methotrexate $(3 \mathrm{~m}$ ) with vincristine, anthracycline and cyclophosphamide (Vac) in advanced breast-cancer. Br J Cancer. 1991;64:406-10.

52. Julka PK, Chacko RT, Nag S, Parshad R, Nair A, Koppiker CB, et al. A phase 2 study of sequential neoadjuvant chemotherapy with gemcitabine and doxorubicin followed by gemcitabine and cisplatin in patients with large or locally advanced operable breast cancer: results from long-term follow-up. Breast Cancer. 2013;20:357-62.

53. Livi L, Saieva C, Borghesi S, Paoletti L, Meattini I, Rampini A, et al. Concurrent cyclophosphamide, methotrexate, and 5-fluorouracil chemotherapy and radiotherapy for early breast carcinoma. Int J Radiat Oncol Biol Phys. 2008;71:705-9.

54. Satoh M, Cherian MG, Imura N, Shimizu H. Modulation of resistance to anticancer drugs by inhibition of metallothionein synthesis. Cancer Res. 1994;54:5255-7.

55. Zhao YB, Lu HL, Yan A, Yang YM, Meng QW, Sun LC, et al. ABCC3 as a marker for multidrug resistance in non-small cell lung cancer. Sci Rep. 2013; 3:3120.

56. Li QD, Yu JJ, Mu CJ, Yunmbam MK, Slavsky D, Cross CL, et al. Association between the level of ERCC-1 expression and the repair of cisplatin-induced DNA damage in human ovarian cancer cells. Anticancer Res. 2000;20:645-52.

57. Ma JJ, Chen BL, Xin XY. XIAP gene downregulation by small interfering RNA inhibits proliferation, induces apoptosis, and reverses the cisplatin resistance of ovarian carcinoma. Eur J Obstet Gynecol Reprod Biol. 2009;146:222-6.

58. Goto S, lida T, Cho S, Oka M, Kohno S, Kondo T. Overexpression of glutathione S-transferase pi enhances the adduct formation of cisplatin with glutathione in human cancer cells. Free Radic Res. 1999;31:549-58.

59. Hansen RK, Parra I, Lemieux P, Oesterreich S, Hilsenbeck SG, Fuqua SAW. Hsp27 overexpression inhibits doxorubicin-induced apoptosis in human breast cancer cells. Breast Cancer Res Treat. 1999;56:187-96.

60. Yap XL, Tan HY, Huang JX, Lai YY, Yip GWC, Tan PH, et al. Over-expression of metallothionein predicts chemoresistance in breast cancer. J Pathol. 2009;217:563-70.

61. Li LH, Dong H, Zhao F, Tang J, Chen X, Ding J, et al. The upregulation of dihydropyrimidine dehydrogenase in liver is involved in acquired resistance to 5-fluorouracil. Eur J Cancer. 2013;49:1752-60.

62. Davidson JD, Ma LD, Flagella M, Geeganage S, Gelbert LM, Slapak CA. An increase in the expression of ribonucleotide reductase large subunit 1 is associated with gemcitabine resistance in non-small cell lung cancer cell lines. Cancer Res. 2004;64:3761-6.
63. Langlands FE, Horgan K, Dodwell DD, Smith L. Breast cancer subtypes: response to radiotherapy and potential radiosensitisation. Br J Radiol. 2013;86:20120601.

64. Li JY, Li YY, Jin W, Yang Q, Shao ZM, Tian XS. ABT-737 reverses the acquired radioresistance of breast cancer cells by targeting $\mathrm{BCl}-2$ and $\mathrm{BCl}-\mathrm{xL}$. J Exp Clin Cancer Res. 2012;31:102.

65. Kurrey NK, Jalgaonkar SP, Joglekar AV, Ghanate AD, Chaskar PD, Doiphode RY, et al. Snail and slug mediate radioresistance and chemoresistance by antagonizing p53-mediated apoptosis and acquiring a stem-like phenotype in ovarian cancer cells. Stem Cells. 2009;27:2059-68.

66. Vakifahmetoglu $\mathrm{H}$, Olsson M, Zhivotovsky B. Death through a tragedy: mitotic catastrophe. Cell Death Differ. 2008;15:1153-62

67. Kroemer G, Galluzzi L, Vandenabeele P, Abrams J, Alnemri ES, Baehrecke EH, et al. Classification of cell death: recommendations of the Nomenclature Committee on Cell Death 2009. Cell Death Differ. 2009;16:3-11.

68. Biade S, Stobbe CC, Chapman JD. The intrinsic radiosensitivity of some human tumor cells throughout their cell cycles. Radiat Res. 1997;147:416-21.

69. Pawlik TM, Keyomarsi K. Role of cell cycle in mediating sensitivity to radiotherapy. Int J Radiat Oncol Biol Phys. 2004;59:928-42.

70. Jameel JK, Rao VS, Cawkwell L, Drew PJ. Radioresistance in carcinoma of the breast. Breast. 2004;13:452-60.

71. Kobunai T, Watanabe T, Fukusato T. REG4, NEIL2, and BIRC5 gene expression correlates with gamma-radiation sensitivity in patients with rectal cancer receiving radiotherapy. Anticancer Res. 2011;31:4147-53.

72. Awasthi S, Singhal SS, Yadav S, Singhal J, Drake K, Nadkar A, et al. RLIP76 is a major determinant of radiation sensitivity. Cancer Res. 2005;65:6022-8.

73. Kawashima A, Nakayama M, Kakuta Y, Abe T, Hatano K, Mukai M, et al. Excision repair cross-complementing group 1 may predict the efficacy of chemoradiation therapy for muscle-invasive bladder cancer. Clin Cancer Res. 2011;17:2561-9.

74. Tomaskovic-Crook E, Thompson EW, Thiery JP. Epithelial to mesenchymal transition and breast cancer. Breast Cancer Res. 2009;11:213.

75. Teschendorff AE, Journee M, Absil PA, Sepulchre R, Caldas C. Elucidating the altered transcriptional programs in breast cancer using independent component analysis. PLoS Comput Biol. 2007;3:e161.

76. Mironchik Y, Winnard Jr PT, Vesuna F, Kato Y, Wildes F, Pathak AP, et al. Twist overexpression induces in vivo angiogenesis and correlates with chromosomal instability in breast cancer. Cancer Res. 2005;65:10801-9.

77. Lee K, Nelson CM. New insights into the regulation of epithelial-mesenchymal transition and tissue fibrosis. Int Rev Cell Mol Biol. 2012;294:171-221.

78. Lee K, Gjorevski N, Boghaert E, Radisky DC, Nelson CM. Snail1, Snail2, and E47 promote mammary epithelial branching morphogenesis. EMBO J. 2011;30:2662-74

79. Aybar MJ, Nieto MA, Mayor R. Snail precedes slug in the genetic cascade required for the specification and migration of the Xenopus neural crest. Development. 2003;130:483-94.

80. Dhasarathy A, Kajita M, Wade PA. The transcription factor snail mediates epithelial to mesenchymal transitions by repression of estrogen receptor-alpha. Mol Endocrinol. 2007;21:2907-18.

81. Ye Y, Xiao Y, Wang W, Yearsley K, Gao JX, Barsky SH. ERalpha suppresses slug expression directly by transcriptional repression. Biochem J. 2008:416:179-87.

82. Azmi AS, Bollig-Fischer A, Bao B, Park BJ, Lee SH, Yong-Song G, et al. Systems analysis reveals a transcriptional reversal of the mesenchymal phenotype induced by SNAIL-inhibitor GN-25. BMC Syst Biol. 2013;7:85.

83. Guaita S, Puig I, Franci C, Garrido M, Dominguez D, Batlle E, et al. Snail induction of epithelial to mesenchymal transition in tumor cells is accompanied by MUC1 repression and ZEB1 expression. J Biol Chem. 2002;277:39209-16.

84. Taki M, Verschueren K, Yokoyama K, Nagayama M, Kamata N. Involvement of Ets-1 transcription factor in inducing matrix metalloproteinase-2 expression by epithelial-mesenchymal transition in human squamous carcinoma cells. Int J Oncol. 2006;28:487-96.

85. Bracken CP, Gregory PA, Kolesnikoff N, Bert AG, Wang J, Shannon MF, et al. A double-negative feedback loop between ZEB1-SIP1 and the microRNA-200 family regulates epithelial-mesenchymal transition. Cancer Res. 2008;68:7846-54.

86. Wels $\mathrm{C}$, Joshi $\mathrm{S}$, Koefinger $\mathrm{P}$, Bergler $\mathrm{H}$, Schaider $\mathrm{H}$. Transcriptional activation of ZEB1 by Slug leads to cooperative regulation of the epithelial-mesenchymal transition-like phenotype in melanoma. J Invest Dermatol. 2011;131:1877-85.

87. Ding X, Park SI, McCauley LK, Wang CY. Signaling between transforming growth factor beta (TGF-beta) and transcription factor SNAI2 represses expression of microRNA miR-203 to promote epithelial-mesenchymal transition and tumor metastasis. J Biol Chem. 2013;288:10241-53. 
88. Zhang B, Zhang Z, Xia S, Xing C, Ci X, Li X, et al. KLF5 activates microRNA 200 transcription to maintain epithelial characteristics and prevent induced epithelial-mesenchymal transition in epithelial cells. Mol Cell Biol. 2013:33:4919-35.

89. Roy SS, Gonugunta VK, Bandyopadhyay A, Rao MK, Goodall GJ, Sun LZ, et al. Significance of PELP1/HDAC2/miR-200 regulatory network in EMT and metastasis of breast cancer. Oncogene. 2014;33:3707-16.

90. Zeller Kl, Zhao X, Lee CW, Chiu KP, Yao F, Yustein JT, et al. Global mapping of c-Myc binding sites and target gene networks in human B cells. Proc Natl Acad Sci U S A. 2006;103:17834-9.

91. Dhasarathy A, Phadke D, Mav D, Shah RR, Wade PA. The transcription factors Snail and Slug activate the transforming growth factor-beta signaling pathway in breast cancer. PLoS One. 2011;6:e26514.

92. Taube JH, Herschkowitz Jl, Komurov K, Zhou AY, Gupta S, Yang J, et al. Core epithelial-to-mesenchymal transition interactome gene-expression signature is associated with claudin-low and metaplastic breast cancer subtypes. Proc Natl Acad Sci U S A. 2010;107:15449-54.

93. Shirakihara T, Saitoh M, Miyazono K. Differential regulation of epithelial and mesenchymal markers by deltaEF1 proteins in epithelial mesenchymal transition induced by TGF-beta. Mol Biol Cell. 2007;18:3533-44.

94. Radisky DC, Levy DD, Littlepage LE, Liu H, Nelson CM, Fata JE, et al. Rac1b and reactive oxygen species mediate MMP-3-induced EMT and genomic instability. Nature. 2005;436:123-7.

95. Lou H, Kaplowitz N. Glutathione depletion down-regulates tumor necrosis factor alpha-induced NF-kappaB activity via IkappaB kinase-dependent and -independent mechanisms. J Biol Chem. 2007:282:29470-81.

96. Reinhold WC, Reimers MA, Lorenzi P, Ho J, Shankavaram UT, Ziegler MS, et al. Multifactorial regulation of E-Cadherin expression: an integrative study. Mol Cancer Ther. 2010;9:1-16

97. Byers LA, Diao LX, Wang J, Saintigny P, Girard L, Peyton M, et al. An epithelial-mesenchymal transition gene signature predicts resistance to EGFR and PI3K Inhibitors and Identifies axl as a therapeutic target for overcoming egfr inhibitor resistance. Clin Cancer Res. 2013;19:279-90.

98. Arumugam T, Ramachandran V, Fournier KF, Wang H, Marquis L, Abbruzzese $J$, et al. Epithelial to mesenchymal transition contributes to drug resistance in pancreatic cancer. Cancer Res. 2009;69:5820-8.

99. Soon L, Tachtsidis A, Fok S, Williams ED, Newgreen DF, Thompson EW. The Continuum of Epithelial Mesenchymal Transition - Implication of Hybrid States for Migration and Survival in Development and Cancer. In: Lyden D, Welch D, Psaila B, editors. Cancer metastasis: biologic basis and therapeutics. New York: Cambridge University Press; 2011.

100. Santisteban M, Reiman JM, Asiedu MK, Behrens MD, Nassar A, Kalli KR, et al. Immune-induced epithelial to mesenchymal transition in vivo generates breast cancer stem cells. Cancer Res. 2009;69:2887-95.

101. Pajonk F, Vlashi E, McBride WH. Radiation resistance of cancer stem cells: the 4 R's of radiobiology revisited. Stem Cells. 2010;28:639-48.

102. Kobayashi Cl, Suda T. Regulation of reactive oxygen species in stem cells and cancer stem cells. J Cell Physiol. 2012;227:421-30.

103. Fong $H$, Hohenstein KA, Donovan PJ. Regulation of self-renewal and pluripotency by Sox2 in human embryonic stem cells. Stem Cells. 2008;26:1931-8.

104. Campbell PA, Perez-Iratxeta C, Andrade-Navarro MA, Rudnicki MA. Oct4 targets regulatory nodes to modulate stem cell function. PLoS One. 2007;2:e553.

105. Okita K, Ichisaka T, Yamanaka S. Generation of germline-competent induced pluripotent stem cells. Nature. 2007:448:313-7.

106. Marcato P, Dean CA, Pan D, Araslanova R, Gillis M, Joshi M, et al. Aldehyde dehydrogenase activity of breast cancer stem cells is primarily due to isoform ALDH1A3 and its expression is predictive of metastasis. Stem Cells. 2011;29:32-45

107. Liu Y, Nenutil R, Appleyard MV, Murray K, Boylan M, Thompson AM, et al. Lack of correlation of stem cell markers in breast cancer stem cells. Br J Cancer. 2014;110:2063-71.

108. Ding XW, Wu JH, Jiang CP. ABCG2: a potential marker of stem cells and novel target in stem cell and cancer therapy. Life Sci. 2010;86:631-7.

109. Guo W, Keckesova Z, Donaher JL, Shibue T, Tischler V, Reinhardt F, et al. Slug and Sox9 cooperatively determine the mammary stem cell state. Cell. 2012;148:1015-28.

\section{Submit your next manuscript to BioMed Central and we will help you at every step:}

- We accept pre-submission inquiries

- Our selector tool helps you to find the most relevant journal

- We provide round the clock customer support

- Convenient online submission

- Thorough peer review

- Inclusion in PubMed and all major indexing services

- Maximum visibility for your research

Submit your manuscript at www.biomedcentral.com/submit
Biomed Central 